Illinois State University

ISU ReD: Research and eData

Theses and Dissertations

$9-27-2018$

\title{
The Influence Of Social And Economic Factors On Breastfeeding And Rural Mothers
}

Rachel Ellen Borton

Illinois State University, rborton@bradley.edu

Follow this and additional works at: https://ir.library.illinoisstate.edu/etd

Part of the Nursing Commons

\section{Recommended Citation}

Borton, Rachel Ellen, "The Influence Of Social And Economic Factors On Breastfeeding And Rural Mothers" (2018). Theses and Dissertations. 1006.

https://ir.library.illinoisstate.edu/etd/1006

This Dissertation is brought to you for free and open access by ISU ReD: Research and eData. It has been accepted for inclusion in Theses and Dissertations by an authorized administrator of ISU ReD: Research and eData. For more information, please contact ISUReD@ilstu.edu. 


\section{THE INFLUENCE OF SOCIAL AND ECONOMIC FACTORS ON BREASTFEEDING AND RURAL MOTHERS}

\section{RACHEL ELLEN BORTON}

68 Pages

Little is known or understood about rural mothers and their experience with breastfeeding. The literature demonstrates a sound understanding of the factors that influence mothers and breastfeeding; however, it is unclear what factors influence breastfeeding among rural mothers. A search of the literature offered thousands of articles related to urban mothers and their breastfeeding experience, but few describe the rural mother's breastfeeding experience. Therefore, the purpose of this study is to investigate the basic process that characterizes breastfeeding among mothers in the rural setting and to develop a theory based on the investigation of factors that influence breastfeeding among rural mothers. Because little is known, a grounded theory approach provides the best avenue to investigate the interactions between mother and baby. This study attempts to address the current information gap related to rural mothers and their breastfeeding experience. Health care providers in rural areas face many challenges to providing breastfeeding support and services to mothers. Both rural hospitals and rural communities have breastfeeding gaps. Rural mothers experience access barriers to breastfeeding support; however, some can overcome breastfeeding barriers. Hospital nurses and lactation consultants who demonstrate specific support characteristics can provide rural mothers with breastfeeding support that could significantly impact rural health outcomes.

KEYWORDS: Breastfeeding, Rural Mothers, Mothers Breastfeeding, Breastfeeding Barriers 


\section{THE INFLUENCE OF SOCIAL AND ECONOMIC FACTORS ON BREASTFEEDING AND RURAL MOTHERS}

RACHEL ELLEN BORTON

A Dissertation Submitted in Partial

Fulfillment of the Requirements for the Degree of

DOCTOR OF PHILOSOPHY

Mennonite College of Nursing

ILLINOIS STATE UNIVERSITY

2018 
(C) 2018 Rachel Ellen Borton 


\section{THE INFLUENCE OF SOCIAL AND ECONOMIC FACTORS ON BREASTFEEDING AND RURAL MOTHERS}

RACHEL ELLEN BORTON

COMMITTEE MEMBERS:

Carla J. Pohl, Chair

Peggy Flannigan

Sheryl Jenkins

Cindy Kerber 


\section{ACKNOWLEDGMENTS}

I would like to thank each mother who shared her breastfeeding experience and made this study possible. The MCN at ISU Dissertation Research Grant supported this effort. Bradley University for financially supporting my doctoral studies and the Department of Nursing for providing flexibility with scheduling and permitting my ISU attendance. My advisor Carla provided me with direction on this learning path. Each of my family members supported my doctoral work in their own way: babysitting, listening, and prayers for me to finish. To my parents, thank you for teaching me at a young age how to work hard; little did I know, those were just the stepping-stones. To my four children, thank you for being so understanding when Momma had "school" to work on and could not watch a movie or stay up late with you. I hope my efforts have shown each of you that no matter how challenging a task may be, don't give up, keep pushing forward, and you will finish and accomplish your goal! To my husband, thank you for my sanity. Thank you for always listening to me, defending my efforts, and problem solving at midnight when my academic world seemed to be crashing in around me. I love you and could not have done this without you. Thank you, God, for giving me the ability to persevere and the comfort to keep going.

R.E.B. 


\section{CONTENTS}

Page

ACKNOWLEDGMENTS

$\begin{array}{ll}\text { CONTENTS } & \text { ii }\end{array}$

CHAPTER I: THE RURAL MOTHER AND BREASTFEEDING REVIEW OF

LITERATURE

$\begin{array}{ll}\text { Abstract } & 1\end{array}$

Purpose/Aims

Search Methods and Results for Integrative Review 2

Integrative Review 3

Breastfeeding Rates 3

Access and Availability 4

Rural Access

$\begin{array}{ll}\text { Socioeconomic Status } & 6\end{array}$

$\begin{array}{ll}\text { Education } & 8\end{array}$

$\begin{array}{ll}\text { Employment } & 9\end{array}$

Synthesis of Results $\quad 10$

$\begin{array}{ll}\text { Access and Availability } & 10\end{array}$

Decreased Breastfeeding 11

Low Income 11

$\begin{array}{ll}\text { Education } & 12\end{array}$

$\begin{array}{ll}\text { Return to Work } & 12\end{array}$

$\begin{array}{ll}\text { Conclusion } & 12\end{array}$ 
Recommendations for Future Research

CHAPTER II: THE INFLUENCE OF SOCIAL AND ECONOMIC FACTORS ON BREASTFEEDING AND RURAL MOTHERS

Abstract

Introduction

Problem

Literature Review

Low Socioeconomic Status

Less Education

Disparate Breastfeeding Support

Return to Work

Research Design and Methods

Triangulation

Trustworthiness

Reflexivity

Protections for Human Subjects/Participation Rights

The Setting, Target Population, and Sample

Sampling Strategy

Procedure

Data Analysis

Results

Grounding Process 
$\begin{array}{ll}\text { Definitions } & 26\end{array}$

$\begin{array}{ll}\text { Breastfeeding Success Context } & 26\end{array}$

Matters of the Heart $\quad 26$

$\begin{array}{ll}\text { Support to Succeed } & 28\end{array}$

Steps Taken Towards Breastfeeding Success $\quad 30$

$\begin{array}{ll}\text { Emerging Themes } & 33\end{array}$

$\begin{array}{ll}\text { Discussion } & 34\end{array}$

$\begin{array}{ll}\text { Limitations } & 36\end{array}$

$\begin{array}{ll}\text { Implications } & 36\end{array}$

$\begin{array}{ll}\text { Conclusion } & 37\end{array}$

CHAPTER III: LESSONS LEARNED FROM MANAGING RESEARCH WITH RURAL

$\begin{array}{ll}\text { MOTHERS } & 38\end{array}$

$\begin{array}{ll}\text { Abstract } & 38\end{array}$

$\begin{array}{ll}\text { Introduction } & 38\end{array}$

$\begin{array}{ll}\text { Background } & 39\end{array}$

Rural Breastfeeding Barriers $\quad 39$

$\begin{array}{ll}\text { Lessons Learned } & 42\end{array}$

Stakeholder Buy-In $\quad 42$

Sample Characteristics $\quad 43$

Identifying with Participants and Nurses $\quad 44$

Recommendations for Action $\quad 44$

Lesson One: Stakeholder Buy-In $\quad 45$

Lesson Two: Incentives $\quad 45$ 
$\begin{array}{ll}\text { Conclusion } & 46\end{array}$

$\begin{array}{ll}\text { REFERENCES } & 47\end{array}$

APPENDIX A: FIGURES AND TABLES FROM CHAPTER I: THE RURAL MOTHER AND BREASTFEEDING REVIEW OF LITERATURE

APPENDIX B: FIGURES, TABLES, AND SUPPLEMENTAL MATERIAL FROM

CHAPTER II: THE INFLUENCE OF SOCIAL AND ECONOMIC FACTORS ON

BREASTFEEDING AND RURAL MOTHERS

APPENDIX C: FIGURE FROM CHAPTER III: LESSONS LEARNED FROM

MANAGING RESEARCH WITH RURAL MOTHERS

68 


\title{
CHAPTER I: THE RURAL MOTHER AND BREASTFEEDING REVIEW OF LITERATURE
}

Chapter I is an integrative review of literature that identifies the known factors associated with rural mothers' breastfeeding experience, such as poor breastfeeding rates, low socioeconomic status, little education, a quick return to work, and disparate breastfeeding support. This article has been prepared for publication in the Journal of Rural Health.

\begin{abstract}
Although the literature is saturated with articles related to urban mothers and breastfeeding, little is known or understood about the rural population of mothers and their experience with breastfeeding. Current literature offers thousands of articles related to urban mothers and their breastfeeding experience, but few describe rural mother's breastfeeding experience. This review revealed that rural mothers have low breastfeeding rates and face challenges in access and availability of breastfeeding support. They also may have less education, lower socioeconomic status, and decreased access to healthcare as compared to their urban counterparts. Perhaps, rural geographic location negatively impacts breastfeeding among rural mothers. Further investigation into rural mothers' breastfeeding experience may ultimately improve breastfeeding rates and knowledge about access and availability of breastfeeding support.
\end{abstract}

\section{Purpose/Aims}

Although more than a thousand publications exist regarding breastfeeding and breastfeeding interventions, only a handful of studies speak to the rural mother and breastfeeding. Rural populations have low breastfeeding rates (Wilhelm, Aguirre, Koehler, \& Rodehorst, 2015). Access and availability of breastfeeding support are challenges for rural mothers (Jacobson et al., 2015). Rural mothers return to work quickly. Researchers have a good 
understanding of the factors that influence mothers and breastfeeding; however, it is unclear what factors influence breastfeeding among mothers in the rural setting. The purpose of this literature review is to determine what is known about breastfeeding rates, availability and access support, impact of education, socioeconomic status and employment among rural mothers.

\section{Search Methods and Results for Integrative Review}

A search of rural mothers' breastfeeding experiences yielded 1,169 studies in PubMed, 62 studies in CINAHL, and 742 studies in Research Gate. After applying inclusion criteria, acceptable studies were obtained: four in PubMed and four in CINAHL (see Appendix A). Inclusion criteria were peer-reviewed studies that examined breastfeeding support interventions to increase breastfeeding in the rural United States, years 2002-2018, and interactions between social and economic status and breastfeeding. Exclusion criteria were studies with high-risk mothers, women who had preterm infants, infants admitted to special-care nurseries, noninterventional studies, and studies outside the continental United States. Search terms included breastfeeding, breastfeeding rates, mothers, rural mothers, rural breastfeeding, breastfeeding access, support, and WIC mothers in various combinations attempting to capture the literature available regarding rural mothers and breastfeeding.

In one such search strategy, the following combination of terms was used: breastfeeding OR mothers breastfeeding OR mothers and breastfeeding interventions. This approach yielded more than 15,000 articles. Due to the significant number of results, the first 250 articles were scanned to assess their relevance to mothers and breastfeeding. Multiple themes appeared: breastfeeding in high-risk mothers (HIV-positive mothers and smoking mothers), breastfeeding and high-risk infants (infants with Down syndrome and preterm infants), breastfeeding and 
workplace, urban mothers and breastfeeding, breastfeeding in third-world countries, breast milk and nutrition, and breastfeeding and cultural practices.

In order to narrow the search results based on the research focus, the following combination of terms was used in the next search strategy: breastfeeding AND rural mothers OR breastfeeding interventions AND rural mothers AND rural and breastfeeding. This approach resulted in more than 1,800 articles. Titles were reviewed for significance, and duplicates were removed, resulting in 189 articles. Inclusion and exclusion criteria were applied to authenticate the articles for use: 181 were rejected, and 8 were retained for further consideration (see Appendix A). All the studies reviewed about rural breastfeeding mothers demonstrated consistent characteristics: WIC participation, lower socioeconomic status, lack of education education, barriers to health care, early return to work, and Special Supplemental Nutrition Program for Women, Infants, and Children (WIC) participation. The following themes became evident throughout this integrative review: access to breastfeeding support, rural geographical location, breastfeeding rates, lower income, and employment.

\section{Integrative Review}

\section{Breastfeeding Rates}

Breastfeeding rates increased between 2011 (74.6\%) and 2015 (83.2\%) in the United States (CDC, 2018). However, mothers living in rural areas consistently maintain lower rates of breastfeeding when compared to their urban counterparts (Wilhelm et al., 2015). The Center for Disease and Prevention (CDC, 2018) conducts a quarterly telephone National Immunization Survey (NIS, 2015) and based on the most recent data stated "Infants in rural areas are less likely to ever breastfeed than infants living in urban areas.” Allen, Perrine, and Scanlon (2015) performed a retro-case analysis study among rural and urban hospitals, examining whether 
hospital maternity care practices differ according to geographic location. The researchers identified a breastfeeding variation among mothers and infants in the research study: $83.5 \%$ of urban infants were breastfed, while only $71.4 \%$ of rural infants were breastfed. The Center for Disease and Prevention (CDC, 2018) conducts a quarterly telephone National Immunization Survey (NIS, 2015) and based on the most recent data stated, "Infants in rural areas are less likely to ever breastfeed than infants living in urban areas."

\section{Access and Availability}

The Merriam-Webster Online Dictionary defines access as the "permission, liberty, or ability to enter, approach or pass to and from a place" (Access, n.d.). Healthcare access is the opportunity to have healthcare needs fulfilled (Levesque, Harris, \& Russel, 2013). Researchers defined access through five dimensions of accessibility: approachability, acceptability, availability and accommodation, affordability, and appropriateness. Having breastfeeding support is critical to breastfeeding success and duration (Levesque et al., 2013).

Diminished access and availability to breastfeeding support negatively impacts breastfeeding success. Cross-Barnet, Augustyn, Gross, Resnik, and Paige (2012) performed a qualitative study, with an explanatory approach, to examine the breastfeeding experiences of WIC mothers from health department agencies in Maryland. A convenience sample of 75 mothers was recruited from three separate Maryland WIC health department agencies: one urban, one rural, and one suburban. Mothers reported receiving breastfeeding education only one time: either prenatally, immediately postpartum, or during the child's infancy. The mothers said that information obtained was insufficient and sometimes incorrect and that providers were often aggressive and unresponsive to the mother's breastfeeding support needs. Cross-Barnet and colleagues (2012) conclude that offering consistent breastfeeding support through all three 
stages — prenatally, immediately postpartum, and during pediatric office visits — is critical to breastfeeding success.

\section{Rural Access}

The U. S. Census Bureau defines rural as any geographic location that is not urban (Ratliffe, Burd, Holder, \& Field, 2016). Urban is defined as all territory, population, and housing units in geographic areas with a population of more than 50,000 persons (Ratliffe et al., 2016). Jacobson and colleagues (2015) asserted that access and availability of breastfeeding services is a significant component in breastfeeding success for rural mothers.

Studies of rural mothers demonstrate that rural geographic access appears to have a negative impact on breastfeeding. Jacobson and colleagues (2015) conducted a multivariable binary logistic regression study to identify maternal characteristics associated with breastfeeding among rural versus urban mothers living in Kansas. A convenience sample of 17,309 WIC mothers participated in the study. The researchers discovered that WIC participants living in rural areas had higher rates of smoking and also had less access to prenatal and breastfeeding support than women receiving WIC assistance residing in urban locations (Jacobson et al., 2015).

Goodman, Majee, Olsberg, and Jefferson (2016) and Allen, Perrine, and Scanlon (2015) compared urban hospitals with rural hospitals. Goodman et al. (2016) discovered significant gaps in hospital and community breastfeeding support. Given the low-income status of the rural mothers, the researchers determined that a large support team, including community stakeholders, be instituted to further breastfeeding duration. The rural mother's breastfeeding experience was found to be a missing piece of breastfeeding facilitation (Goodman et al., 2016). Providers found that although breastfeeding support was provided during the hospital stay, once mothers were discharged home, the support ended. Breastfeeding support beyond discharge was 
found to be a critical link to achieving breastfeeding success (Goodman et al., 2016). Rural locations, with their smaller populations, are frequently overlooked in allocating funding for breastfeeding support (Allen et al., 2015). Although a smaller population is being reached, the rural group is a distinct group that would benefit from access to culturally sensitive care, particularly related to breastfeeding support practices (Allen et al., 2015). Findings from both studies reveal that more heavily populated urban areas have a better chance of receiving funding for breastfeeding support because the increased health outcomes will affect a larger number of people (Allen et al., 2015 \& Goodman et al., 2016).

Availability of maternal healthcare services, following infant delivery, to rural women is critical to breastfeeding success. In spite of the availability of educational materials for new mothers, some in-person educational interaction is required for breastfeeding success (Gazmararian et al., 2014). A two-part qualitative methodology study was completed with both urban and rural first-time mothers (Gazmararian et al., 2014). Researchers determined that quality materials are available to new mothers: however, most mothers wished to receive this information in person during postpartum follow-up visits, not during their hospital stay (Gazmararian et al., 2014). Rural mothers often have to travel long distances to receive health care access, and most maternal services offered are limited (Goodman et al., 2016). Improved healthcare access and in-person breastfeeding educational interaction can improve rural maternal and infant healthcare outcomes (Goodman et al., 2016).

\section{Socioeconomic Status}

Socioeconomic status is defined as "an individual's or group's position within a hierarchical social structure." Multiple variables, including occupation, education, income, wealth, and place of residence," describe and define a person's socioeconomic status 
(Socioeconomic status, 2018). Breastfeeding duration is affected both positively and negatively by socioeconomic status: Low-income status appears to lower breastfeeding length, and highincome status has a positive impact on breastfeeding with longer breastfeeding duration (Jacobson et al., 2015).

Persad and Mensinger (2008) completed a descriptive analysis of sociodemographic characteristics, breastfeeding, and breastfeeding attitudes of primiparas (women pregnant for the first time) presenting to an urban hospital. Mickens, Modeste, Montgomery, and Taylor (2009) used multivariable logistic regression to explore breastfeeding in low-income women's infant feeding decisions. Both studies demonstrated that low-income mothers earning less than $\$ 30,000$ a year were less likely to breastfeed and that these mothers should be targeted for breastfeeding interventions (Mickens et al., 2009; Persad \& Mesinger, 2008).

Low-income jobs can interfere with breastfeeding success. Goodman and colleagues (2016) interviewed both providers and breastfeeding mothers to determine what barriers existed in the rural community. Rural mothers often have low-income jobs and could benefit from having a breastfeeding team of support-one that extends beyond hospital discharge (Goodman et al., 2016). One provider explained that there was enormous pressure for these mothers to return to work quickly.

Murimi, Dodge, Pope, and Erickson (2010) completed a cross-sectional study with lowincome rural mothers in Central Louisiana who received WIC benefits. The researchers discovered that:

- Early postpartum assistance with breastfeeding was critical to breastfeeding success 
- Existing WIC enticements did not appear to play a role in the breastfeeding decision

- Availability of formula did not seem to impact a mother's decision to breastfeed

- If the mother herself had been breastfed, she was more likely to breastfeed (Murimi et al., 2010).

\section{Education}

Some rural mothers have less education. The United States Census Bureau (USCB) concluded that between $20 \%-30 \%$ of rural women have bachelors' degrees or higher, compared to $30 \%-40 \%$ of urban women (Day, Hays, \& Smith, 2016). Jacobson and colleagues (2015) examined breastfeeding traits of urban and rural mothers receiving WIC. Urban mothers receiving WIC support who had more than a high school education and earned more than $\$ 10,000$ a year had higher rates of breastfeeding. Both urban and rural mothers who had more than a high school education were more likely to breastfeed (Jacobson et al., 2015). Flower and colleagues (2008) completed a longitudinal cohort and parallel ethnographic study to investigate factors associated with breastfeeding among rural mothers. Rural mothers most frequently had some high school education or had graduated from high school but earned less than $20 \%$ of the U.S. federal poverty level guidelines. Goodman et al. (2016) found that most rural mothers had completed high school, but few had experienced college education.

Wilhelm, Aguirre, Koehler, and Rodehorst (2015) completed a two-group repeated measures study, which provided a motivational intervention to postpartum, Hispanic rural mothers. Overall, there were high levels of participant attrition, and the results were not statistically significant. Sixty-eight percent of the mothers sampled $(n=36)$ had less than a high school education. The researchers determined that time spent before study implementation is 
critical to establish relationships with mothers and all community stakeholders to support study retention (Wilhelm et al., 2015).

\section{Employment}

The U.S. Department of Labor (DOL) reported that $57 \%$ of employees are women (2015). Sixty-two percent of the national female workforces are new mothers, who have given birth and returned to work within 12 months (DOL, 2015). Goodman and colleagues (2016) showed that early return to work negatively impacts breastfeeding duration. Employed mothers are less likely to work at a facility where a lactation support system is established, let alone experience the opportunity of successful breastfeeding beyond three months (Goodman et al., 2016). Abdulloeva and Eyler (2013) discovered that although the Affordable Care Act amendment of 2010 requires employers to provide reasonable break time for breastfeeding mothers, enforcement falls on state and local officers and does not always occur.

Rural mothers return to work quickly, and many have employers that do not offer breastfeeding support for employees (Goodman et al., 2016). The researchers suggest that employers should be encouraged not only to support but also to facilitate breastfeeding at work. They determined that a workplace lactation consultant could be hired to work strictly with assisting and encouraging employers to support breastfeeding and provide working mothers with breastfeeding accommodations. In addition, they emphasized that the lactation consultant would encourage employers to allow frequent breaks for pumping breast milk and to provide adequate pumping facilities (Goodman et al., 2016).

Flower and colleagues (2008) found that receiving WIC assistance and being employed at two months postpartum were connected with decreased breastfeeding rates for rural mothers. Their findings indicated that many women had not previously considered breastfeeding and 
stopped because they were embarrassed, uncomfortable, and needed support. Although employment specifics were not included in the study, the researchers hypothesized that lack of breastfeeding facilitation at work led to the correlation between maternal employment and breastfeeding cessation, because many mothers returned to jobs where the availability of breastfeeding facilities was less likely.

Hohl, Thompson, Escareno, and Duggan (2016) completed a qualitative, exploratory study and found that Hispanic rural mothers living in Washington State were unable to breastfeed without family and employer support. Participants were more likely to breastfeed if a maternal family member encouraged breastfeeding. Mothers experienced financial pressure to return to work quickly, employers did not facilitate breastfeeding, and most family members felt uncomfortable supplying infants with breast milk while the mother was working. Hohl and colleagues (2016) determined that family interventions and workplace breastfeeding policies are necessary to assist rural Hispanic mothers to achieve optimal breastfeeding rates.

\section{Synthesis of Results}

The studies reviewed (see Table 1) have shown the following factors common to rural mothers who breastfeed: WIC participation, low-income socioeconomic status, breastfeeding support disparities, and early return to work (Flower et al., 2008). The following themes are evident throughout the literature regarding rural mothers: decreased access to breastfeeding support, decreased breastfeeding, low income, high school education (no college), and a quick return to employment time in low support jobs.

\section{Access and Availability}

Rural mothers live in geographic locations with a population of 50,000 people or less. Rural location appears to impact breastfeeding negatively. Literature demonstrates that mothers 
who live in rural locations are more likely to experience gaps in breastfeeding support, breastfeed less, and receive decreased funding for breastfeeding support when compared to mothers who live in urban locations (Allen et al., 2015; Goodman et al., 2016; \& Jacobson et al., 2015). The majority of funding is allocated to densely populated, urban areas, where the health impact can be the greatest (Allen et al., 2015; Goodman et al., 2016; \& Jacobson et al., 2015.

\section{Decreased Breastfeeding}

Allen and colleagues (2015) and Wilhelm and colleagues (2015) identified a breastfeeding rate variation among rural and urban mothers. Urban mothers consistently held higher rates of breastfeeding when compared to rural mothers (Wilhelm et al., 2015). Mothers living in rural areas are less likely to breastfeed than mothers in urban locations (Allen et al., 2015; Wilhelm et al., 2015).

\section{Low Income}

Mothers with low incomes are less likely to breastfeed and those making less than $\$ 30,000$ a year were less likely to breastfeed and would benefit from targeted breastfeeding interventions (Mickens et al., 2009; Persad \& Mesinger, 2008). Some rural mothers have lowincome status and would benefit from receiving breastfeeding support via a team approach (Goodman et al., 2016; Jacobson et al., 2016; Murimi et al., 2010). Many low-income mothers have employers who may not provide health insurance, and mothers may not have transportation to access breastfeeding support. Incorporating all stakeholders involved (the hospital, local health department, and the provider's office) in maternal care is the best approach to providing mothers with breastfeeding support (Goodman et al., 2016). A team approach to breastfeeding can help pool recourses available to provide breastfeeding support (Goodman et al., 2016, Wilhelm et al., 2015). Such as, providing transportation services for low-income individuals, 
assisting with selecting an appropriate health care plan, and encouraging the use of the local health department's breastfeeding peer support specialists.

\section{Education}

The U.S.C.B. demonstrated that rural mothers have less education than urban mothers (Day, Hays, \& Smith, 2016). Researchers compared breastfeeding characteristics and demographics of rural versus urban mothers (Flower et al., 2008; Goodman et al., 2016; Jacobson et al., 2015). In both groups, those mothers with education beyond high school were more likely to breastfeed. Rural mothers were more likely to have only a high school degree, compared to urban mothers who were more likely to have some college education (Flower et al., 2008; Goodman et al., 2016; Jacobson et al., 2015).

\section{Return to Work}

Breastfeeding is negatively impacted by early return to work. Mothers who returned to work within four to six weeks postpartum experienced breastfeeding support disparities, lacked employer breastfeeding support, and would benefit from being able to breastfeed at work (Abdulloeva \& Eyler, 2013; Cottrel \& Detman, 2013; Flower et al., 2008; Goodman et al, 2016; Hohl et al., 2015).

To what extent is lack of support and access to breastfeeding support, low socioeconomic status, little education, and job pressure a factor with breastfeeding among rural mothers? This gap in the literature demonstrates the need to explore these factors that influence breastfeeding among rural mothers.

\section{Conclusion}

The reviewed literature identified the following about rural breastfeeding mothers. Many rural mothers experience decreased access to healthcare, have lower breastfeeding rates, are of 
lower socioeconomic status, have little education, and return to work quickly. Rural geographic location appears to negatively impact breastfeeding among rural mothers. Rural communities receive less funding than urban communities and have significant gaps to fill regarding breastfeeding support for rural mothers. Many rural mothers receive WIC support, and earn less than $\$ 30,000$ a year. High salaries have a positive effect, and low incomes adversely affect breastfeeding. To what extent is lack of support and access to breastfeeding support, low socioeconomic status, little education, and job pressure a factor with breastfeeding among rural mothers? This gap in the literature demonstrates the need to explore these factors that influence breastfeeding among rural mothers.

\section{Recommendations for Future Research}

Future research may focus on determining how minimal access and availability to breastfeeding support, low socioeconomic status, little education, and job pressure may impact breastfeeding among rural mothers. Rural mothers could benefit significantly from a breastfeeding team of support that persists beyond hospital discharge. Many WIC mothers return to work quickly. Employers of low-wage earners do not commonly support breastfeeding, and should not only be educated regarding state laws that protect breastfeeding but also encouraged to create a working environment that supports breastfeeding. A more complete understanding of the rural mother's breastfeeding experience will help determine additional interventions to assist rural mothers with breastfeeding. 


\title{
CHAPTER II: THE INFLUENCE OF SOCIAL AND ECONOMIC FACTORS ON
}

\section{BREASTFEEDING AND RURAL MOTHERS}

In Chapter II the researcher describes the findings of a qualitative, grounded theory study exploring the basic social process that characterizes breastfeeding among mothers in the rural setting. The researcher also develops a substantive theory based on that investigation of factors that influence breastfeeding among rural mothers. The manuscript will be submitted to the Journal of Rural Health or the Maternal and Child Health Journal.

\begin{abstract}
In $2015,83.2 \%$ of American mothers initiated breastfeeding; only $57.6 \%$ continued to breastfeed up to six months. Low-income status is associated with lower rates of breastfeeding initiation and duration. Only $20.1 \%$ of low-income mothers breastfeed for up to six months, and returning to work early has a negative impact on breastfeeding duration. Rural mothers may experience decreased access to breastfeeding support, have a lower income, and return to work more quickly than their urban counterparts. The purpose of this study is to investigate the basic social process that characterizes breastfeeding among mothers in the rural setting and to develop a substantive theory based on the investigation of factors that influence breastfeeding among rural mothers. Because little is known or understood about rural mothers and their experience of feeding their infants, a grounded theory approach provides the best avenue to investigate the interactions between mother and baby. Corbin and Strauss's flexible approach to grounded theory supports the identification of breastfeeding categories and concepts to help construct a mid-range theory. Multiple factors appear to affect the rural population of breastfeeding mothers negatively. Rural mothers are more likely to live at or below the poverty level, have little education, return to work quickly, and experience decreased access to health care when
\end{abstract}


compared to urban mothers. This study has identified a Breastfeeding Success theory that will help mothers overcome breastfeeding barriers and successfully breastfeed in the rural environment.

\section{Introduction}

Breastfeeding is superior to infant formula in that its health advantages benefit both women and infants (Kramer et al., 2008). Maternal benefits of breastfeeding include decreased risk of ovarian cancer, breast cancer, postpartum depression, and type 2 diabetes mellitus; breastfeeding mothers also experience increased post-partum weight loss (Duijts, Jaddoe, Hofman, \& Moll, 2010). Mothers who breastfeed for three months instill their antibodies and provide passive immunity to their infant (McQueen, Dennis, Stremler, \& Normal, 2011). This acquired immunity offers health benefits for infants, such as a decreased incidence of diabetes, obesity, and sudden infant death syndrome.

The Center for Disease Control (CDC) shared encouraging breastfeeding initiation rates of $79.2 \%$ among postpartum women in 2014 . This increased rate reflects all mothers who have tried breastfeeding. However, although breastfeeding initiation rates continue to improve in the United States, disparities exist among ethnicities, income levels, and education levels of rural mothers (Wilhelm, Aquirre, Koehler, \& Rodehortst, 2015).

The American Academy of Pediatrics (2014) and the World Health Organization (WHO, 2016) assert that the ideal duration of breastfeeding practice is 12 to 24 months. Breastfeeding continuation is a challenge in the United States; the CDC (2015) reported that the prevalence of breastfeeding at six months postpartum dropped from $83.2 \%$ to $57.6 \%$. Increased maternal and infant health outcomes are a direct result of breastfeeding practices that extend beyond three to four months (McQueen, Dennis, Stremler, \& Normal, 2011). The U.S. Surgeon General (2010) 
recognized the need to increase breastfeeding duration and issued a call to action in 2011, citing the Healthy People 2020 initiative aimed at increasing breastfeeding duration, to six months.

\section{Problem}

Historically, rural populations live at or below the poverty level and have low breastfeeding rates (Gamm, Hutchinson, Dabney, \& Dorsey, 2003). Only 20.1\% of low-income mothers breastfeed for up to six months, and they report that breastfeeding at work is challenging (Pugh, Milligan, Frick, Spatz, \& Bronner, 2002; Witters-Gree, 2003). Witters-Green (2003) found that low-income mothers receiving Women, Infant, and Children (WIC) support commonly return to work between four and six weeks postpartum. Working mothers reported

that typically, employers designated small spaces for them to express and store breast milk and voiced concerns about taking frequent breaks necessary to express breast milk (Witters-Green, 2003).

Hospital and maternity support services differ according to geographic location; there tend to be lower breastfeeding rates in rural as compared to urban areas (Allen, Perrine, \& Scanlon, 2015). Rural mothers experience decreased access and availability of breastfeeding support resources (Allen et al., 2015). Investigators have a good comprehension of the general aspects that influence breastfeeding among urban mothers (Flowers, Willoughby, Cadigan, Perrin, \& Randolph, 2008), but it is uncertain what aspects influence breastfeeding among rural mothers. Although numerous publications exist regarding breastfeeding, very few studies address the breastfeeding experience among rural mothers (Flowers et al., 2008). This study aims to investigate the social process that characterizes breastfeeding among rural mothers and develop a substantive theory of factors that influence breastfeeding among rural mothers. The ultimate goal of the research is to use that data to help rural mothers become more successful at 
breastfeeding; thus the research question is: What is the experience of breastfeeding among rural mothers?

\section{Literature Review}

Studies concerning rural breastfeeding mothers have demonstrated consistent characteristics: WIC participation, lower socioeconomic status, breastfeeding support disparities, and return to work quickly. The following themes became evident throughout the review: rural geographical location, access to breastfeeding support, income, education, and employment. The following is a brief overview of rural mothers and their characteristics.

\section{Low Socioeconomic Status}

Many rural mothers have a low-income status and participate in the WIC program to receive funding and assistance (Flowers et al., 2008). Persad and Mensinger (2008) found that low-income women living in urban areas are less likely to breastfeed than urban women with higher incomes. Mickens and colleagues (2009) found that mothers making less than $\$ 30,000$ a year were less likely to breastfeed than mothers who made over that amount. An early study by Pugh and colleagues (2002) also found that breastfeeding was impacted by income: mothers with higher incomes breastfeed longer than mothers with lower incomes.

\section{Less Education}

Some rural mothers are less educated than urban mothers (Flowers et al., 2008). The majority of rural mothers have a high school education, but little or no college experience (Flowers et al., 2008). Jacobson and colleagues (2015) compared breastfeeding behaviors in rural mothers to urban mothers living in Kansas. The majority of urban mothers graduated from high school and had some college, while the majority of rural mothers experienced some high school education (Jacobson et al., 2015). Higher education and income level were correlating 
factors with breastfeeding among urban mothers (Jacobson et al., 2015). Lower education and income level were associated with decreased breastfeeding rates among both urban and rural mothers.

\section{Disparate Breastfeeding Support}

Rural hospitals receive less funding than urban hospitals. Allen and colleagues (2015) found that rural locations are less likely to secure funding for breastfeeding support than urban areas. Jacobson and colleagues (2015) discovered that WIC mothers living in rural areas had less access to prenatal and breastfeeding support when compared to WIC mothers living in urban locations. Goodman, Majee, Olsberg, and Jefferson (2016) identified considerable gaps in breastfeeding support in rural hospitals and communities.

\section{Return to Work}

Mothers who return to work quickly are often employed in retail and the service industry. Low-income positions rarely provide the support mothers need to breastfeed at work (WittersGreen, 2003) and many rural mothers return to work quickly. Flowers and colleagues (2008) completed a longitudinal cohort study, which combined qualitative and quantitative methods to study breastfeeding in rural mothers. Return to employment was found to both strongly and negatively impact breastfeeding among rural mothers. Working mothers were less likely to breastfeed after returning to work. The authors concluded that rural mothers commonly worked in jobs lacking breastfeeding support (Flowers et al., 2008).

\section{Research Design and Methods}

Little is known concerning the ways in which rural mothers come to understand the meaning of breastfeeding, what social processes influence their breastfeeding, and what environmental factors affect their breastfeeding experience. Qualitative studies are ideal for 
exploring poorly understood phenomena, such as rural mothers' breastfeeding experiences.

Symbolic interactionism is the process of assessing human interaction to determine meaning among individuals (Blumer, 1969). In this study, the researcher explores the symbolic interactionism between rural mothers and their breastfeeding experience. Grounded theory (GT) provides a unique way to study this social phenomenon, as it offers an explanatory framework with elements for the potential development of breastfeeding interventions (Corbin \& Strauss, 2015). Corbin and Straus (2015) developed a flexible GT approach that begins without a prior existing hypothesis. Their approach utilizes an initial research question--not to make prior assumptions, but to help provide boundaries and concentrate the phenomenon under investigation (Corbin \& Strauss, 2015).

In this study, the researcher invited mothers to share their experience of breastfeeding so that the experiences could be collected through interviews, investigated, and coded into lowerlevel concepts. As data collection occurred from the first theoretical sample of participants, data analysis coincided, and emergent designs in the form of theoretical sampling applied.

\section{Triangulation}

In order to support a comprehensive and well-developed study, triangulation was utilized through various data collection techniques: first and second participant interviews, researcher memos, and researcher observation. Participants were interviewed a single time and then again when secondary interviews were completed. Participants were asked during the second interview if there was anything they would like to add or change. No significant changes were made. Multiple interviews allowed the researcher to receive respondent validation of themes and categories, which emerged from the first interview. Emergent themes from the first interview directed focused questions during the second interview (Corbin \& Strauss, 2015). 


\section{Trustworthiness}

Trustworthiness must be enhanced to improve the credibility of this qualitative research study (Corbin \& Strauss, 2015) and was established through three procedures: validity, rigor, and credibility. Constant comparison, searching for different or negative cases, and data saturation was used throughout the study to provide data validation and protect the validity of the study (Corbin \& Strauss, 2015). Rigor was demonstrated by letting the participants guide the process, checking the theoretical construction with the participant's meanings of the phenomenon, and asking each participant the same interview questions (Corbin \& Strauss, 2015). For example, participants were asked open-ended questions such as, "Would you tell me about breastfeeding your baby?" During the second follow-up phone interview, the researcher confirmed the participant's meanings of the data. Each participant was asked the same openended questions. Credibility was justified through concept validation and verification as concepts were repeated in multiple interviews with different participants and through respondent validation (Corbin \& Strauss, 2015).

\section{Reflexivity}

In order to maintain reflexivity and limit researcher-bias, the researcher utilized two methods: journaling and using the method of GT (Corbin \& Strauss, 2015). Before collecting data the researcher began journaling, identifying why she chose to research breastfeeding experiences and what she personally assumed as breastfeeding knowledge. Journaling continued throughout data collection and analysis. The GT method has some checks and balances in place to help control researcher bias. Previous data collection is compared with new data collection continuously through constant comparison, looking for similarities, differences, and 
consistencies (Corbin \& Strauss, 2015). While researcher bias cannot be eliminated 100\%, journaling and using the method of GT helps to control and limit researcher bias.

\section{Protections for Human Subjects/Participant Rights}

Before data collection, this study received approval from the Institutional Review Board at Illinois State University. Each participant was given a copy of the informed consent (see Appendix A), and the researchers kept one for their records. Throughout the study process, all participants were re-informed regarding the nature of the research and their right to continue or refuse participation. Participants were assigned a confidential number code and codes were stored in a locked box in the PI's locked office. The PI is a nurse practitioner and trained to work with emotionally distressed people. There was a risk that mothers might feel anxious or distressed while recounting their breastfeeding experience and support measures were proactively established. While no anxiety occurred during interviews, all participants received information regarding counselors (See Appendix B) so that appropriate treatment and anxietyreducing measures could be established.

Participants recruited from WIC clinics may have felt the need to answer in such a way as to not endanger their benefits. Most breastfeeding research requires mothers to self-report. The consent form and the PI reminded participants throughout the study that participation was strictly voluntary and mothers could leave at any time without fear of retaliation or loss of WIC benefits.

\section{The Setting, Target Population, and Sample}

The setting for this study was a rural, Midwestern town. The interviews took place in the Health Department and by phone and the target population consisted of rural mothers in the central Midwest. Inclusion criteria were mothers who had given birth in the last three years, were between 18 and 35 years of age, and were able to express themselves in English. Women 
under the age of 18, women over the age of 35, and non-English speaking women were excluded.

\section{Sampling Strategy}

Grounded Theory utilizes theoretical sampling to provide a unique method of data collection (Corbin \& Strauss, 2015). In theoretical sampling, researchers begin with a small sample number of participants and interview them multiple times. Each new interview builds upon concepts from the previous interview. Participants were interviewed in person the first time and then again by phone. Participants were sampled until theoretical saturation was reached and no new concepts emerged from the data under analysis (Corbin \& Strauss, 2015). For the study, the researcher initially recruited a sample of ten participants; up to ten additional participants (for a total $n$ not greater than 20) could be solicited to help confirm emerging concepts and reach data saturation.

\section{Procedure}

The PI recruited breastfeeding mothers during their one-month postpartum follow-up WIC clinic visits. The PI distributed flyers to recruit participants (see Appendix C). Informed consent was obtained, and rural mothers were interviewed in person, during enrollment and four weeks later. The early, unstructured interview consisted of the researcher asking open-ended questions regarding the rural mother's breastfeeding experience, allowing the participants to speak freely (see Appendix D). Question 1: "Think back to when you were pregnant and thought about how to feed your baby. Tell me about that time?" Question number 2: "Would you tell me about breastfeeding your baby?" Participant responses were carefully analyzed and early concepts identified. The PI interviewed the participants via phone and received respondent validation regarding the data collected during the first interview. During the second interview, 
new questions emerged from the data analysis such as, "Can you tell me how the hospital provided you with breastfeeding support?”

Researcher observation assisted with data immersion. The behavior of the population was analyzed via researcher observations taken at the local diner, Walmart, and the Health Department. Descriptive information and reflective information were recorded through field notes. The descriptive information described the physical site, time, actions, behaviors, and conversations heard. Reflective information listed the researcher thoughts, concerns, and questions that arose throughout the observation process (See Appendix F). Observation of local facilities assisted the researcher with cultural and data immersion.

\section{Data Analysis}

All statistical data describing the sample population were analyzed in IBM Statistical Package of the Social Sciences (SPSS) 22.0 (IBM Corp, Armonk, NY, 2013). Collected interview data were coded through the use of NVivo. The population sample was described using the collected demographic data tool and descriptive statistics (See Table 1).

All data were professionally transcribed and reviewed for accuracy by the first researcher and validated by participants in follow-up interviews. Open coding was employed with transcripts, and similar data were grouped. Axial coding was used to link the action-interaction of the lower level concepts to the relationship with the higher level categories or themes (see Figure 1) (Corbin \& Strauss, 2015). Narrative structures were used as a device to organize data into patterns and themes that emerged during analysis (see Diagram 1) (Corbin \& Strauss, 2015).

Memos were written during the first step of data analysis and continued until the final step of data analysis. Memos help to preserve the dialogue of the researcher and denote how concepts are related (Corbin \& Strauss, 2015). For example, the concept of hospital support is 
listed at the top of the memo: next came the participant narrative: then the researcher commentary about the narrative shared: and then finally the researcher commentary of both the memo and diagram (see Appendix E). Memos provide an accurate method of tracking the comprehensive and difficult ideas that change as research shows signs of progress (Corbin \& Strauss, 2015).

\section{Results}

The population sample $(n=10)$ demonstrated that $80 \%$ of mothers had some college education. Exactly half of the women worked outside of the home. The mean age for participants was 30 , and $40 \%$ of the mothers earned less than $\$ 20,000$ a year. Fifty percent of mothers had four members living in their household; $50 \%$ of the mothers were married (See Table 1).

\section{Negative Cases}

Negative cases were identified throughout the final phase of data analysis (Corbin \& Strauss, 2015). Initial analysis revealed categories such as "Provider Support" and "Little Education." As theoretical sampling continued, future interviews did not confirm those cases. For example, during the second set of interviews, participants were asked questions specifically related to the concept of Provider Support, such as, "How did your provider or doctor support you breastfeeding?" While one mother did mention that her provider was instrumental in encouraging her to breastfeed, no other participant had any experience concerning a provider to share, either supportive or not supportive of breastfeeding. In contrast, most participants recounted breastfeeding interactions with hospital nurses and lactation consultants. Data analysis did not confirm the concept of Provider Support, but the concept of Hospital Support was confirmed. Data collection during the third interviews, and follow-up data analysis validated and 
confirmed the new Hospital Support concept, which would ultimately be categorized as External Support. Provider breastfeeding support is always encouraged, but according to this sampled population, not as impactful with breastfeeding support as initially perceived by the Health Department and this researcher.

Studies of rural mothers indicate that rural mothers are often less educated than urban mothers (Flower et al., 2008; Goodman et al., 2016; Jacobson et al., 2015). Contrary to the literature description, the majority of Midwestern mothers sampled did have some college or a college degree. While one participant did have only a high school education, the majority of mothers $(80 \%)$ had some college or a college degree. Consequently, the theme or category of "Little Education" had missing links and became a negative case for the rural breastfeeding mothers research, but did help to provide new insight regarding some rural mothers and their education level.

\section{Grounding Process}

Constant interplay between the data analysis and the data collection "grounded" the analysis from the data (Corbin \& Strauss, 2015). Initial data analysis demonstrated 16 lowerlevel concepts that were then linked to eight higher-level concepts, which were grouped into three categories/themes. Data saturation was reached after no new categories or themes were identified. The higher-level categories/themes became grouped around and helped to explain the "core" category. This process culminated in the development of the single, core category or theme of Breastfeeding Success (See Figure 1). The core social process identified from the data

was "Breastfeeding Success: Steps taken by rural mothers to ensure breastfeeding success." This substantive theory denotes the actions, interactions, and consequences/outcomes taken by mothers breastfeeding in a rural geographic location while interacting with personal and 
environmental factors that encouraged breastfeeding (See Figure 1). The action-interaction data were grouped into three main sub-categories/processes: "Matters of the Heart," "Support to Succeed," and "Steps Taken Toward Breastfeeding Success."

\section{Definitions}

Breastfeeding is defined as the process of a mother feeding her infant with breast milk. Success was defined as mothers being able to breastfeed their infant. Matters of the heart is defined as the process of emotional reactions that rural mothers experienced when breastfeeding. Emotions experienced were described as determination, passion, connection, rewards, and joy. Support to succeed was defined as the process of support that mothers received while breastfeeding. Breastfeeding support was delivered via family members, nursing and lactation staff, and employer support. Steps taken toward breastfeeding success was defined as the process of a series of multiple, various, and intentional steps that mothers took to assist with breastfeeding. The definition of the mother's breastfeeding outcome was identified as the contextual condition in which the process of managing breastfeeding, took place. All mothers interviewed followed one of two different paths or one of two different contexts of breastfeeding outcomes: Breastfeeding Success or Breastfeeding Breakdown.

\section{Breastfeeding Success Context}

\section{Matters of the Heart}

Passion and determination. Some mothers experienced passion and determination regarding the act of breastfeeding. "I was pretty determined I was going to breastfeed successfully this time." Also, one participant said, "I was just determined that I was going to nurse um so I talked to a bunch of different other parents that have nursed and tried to learn all that I could because I struggled with my first child that I nursed." Some mothers described the 
breastfeeding struggle "It is basically determination once you get it set in your mind that you can do it um that there are struggles. But as long as you have determination that you can try different things to get to where you want to be or what your goal is." Breastfeeding mothers experience joy while breastfeeding. "I love it. It's just—its different. I'm so glad that I got to do it this time.” Another participant said, "It was awesome. If I have another child, I hope I get to do it again!"

Rewards experienced. Breastfeeding rewards were described as feeling "empowered and accomplished" and having a better "connection and bond" with their baby. One mother shared, "I just wish a lot, and it's so empowering honestly to breastfeed." Another mother asserted, "I feel like even though it was a challenge, it was something that I'm proud that I accomplished. I feel like it's an accomplishment." One mother encouraged other mothers who do not breastfeed with this advice: "At least try it. I mean even if you're not interested and want to go just straight because it's not only just the best for them obviously, but it is just really a great bonding experience. It's just amazing," and, "It really is a bonding, wholesome experience." Mothers talked about how the bond between mother and infant increases with breastfeeding "I think it increases the bond that you have with your child, and that's rewarding too. It's something that I'm very proud of doing because it wasn't easy." Yet another participant said, "I feel a stronger bond with you know like when he is hungry he can go right to you and just the cues that he's hungry." Moreover, "I was anxious for the bonding experience."

Mothers verbalized that the rewards of breastfeeding outweighed the efforts and challenges and if one makes up their mind to breastfeed they will succeed. "I definitely recommend it to everybody. I tell people — I'm like it's so hard, but it's so worth it." And 
another mother said, "Doing it successfully, is just such a like confidence builder. Honestly to just set a goal like that and accomplish it and then to just have a happy, healthy baby."

Healthcare rewards. Mothers shared healthcare rewards from breastfeeding their infant: "My second child I felt had way less instances of illness with breastfeeding I felt like he grew better; he was just happier. My first one didn't tolerate formula well. She had a lot of tummy troubles with it, and this experience with just breastfeeding is better." Another mother said, "Something I wanted to do to make sure the baby stayed as healthy as possible." One mother described how breastfeeding affected her child's illness "We were in the hospital for one night. Um, he never got too bad with it at all and I just really, I think it's insane and crazy, and I just credit the breastfeeding and the immunity that it does to how well he's handled that." Another participant commented, "Seemed to help her get over her colds quicker." Some mothers spoke to the long-term health benefits of breastfeeding: "If you breastfeed your baby, has less risk of getting you know cancer or diabetes you know all these things. Um, instead they should say formula - if you formula feed your baby, they have a higher risk of getting these things." They also discussed infant nutritional benefits and one mother shared, "Well, nutritional wise, it breaks down in their stomach easier, its better on their digestive system, it is more nutrients."

\section{Support to Succeed}

Family support. Support provided to rural mothers, from family, hospital, and employers were identified as significant contributors to breastfeeding success. Mothers described the support experienced by family members as helping them to breastfeed successfully "My husband was really supportive. He encouraged me, 'if that's what you want to do, do it."' Another mother said, "My family um I mean they helped support it they are all for it. Like I had said something one time cause I was frustrated and my fiancé thought breast milk was the best 
that you could give." One mother experienced emotional support from her family "My sister was there if I needed somebody to cry and be like, oh, I can't do it, I can't do it anymore-like in the first-month stage because that's the hardest." In-laws were helpful with encouraging mothers to breastfeed "My in-laws, just - I don't know, they've always talked about it in a positive way." Another mother shared "My in-laws were kind of — they were like pro-breastfeeding." Parents of breastfeeding mothers who were supportive of breastfeeding provided critical support "They did everything. They helped me with anything to make it last to a year." Having a mother who had breastfed was helpful: "My mom breastfed all of us and then my husband, formula wasn't even a thing that he thought of, so he was like 'You are going to breastfeed, right?"' Another mother said, "Well, having supportive people helped keep it going 'cause not putting it down and saying it's gross and it didn't make me want to give up." One mother confirmed, "My family was very supportive."

Hospital support. Hospital support for breastfeeding is critical to breastfeeding success. A mother shared, "At the hospital, all the OB nurses were always in there checking me making sure the latch was good and was encouraging it and helping." Another mother shared "Yea, we had the three day follow up at the hospital, and they were um, very thorough about asking me how I was feeling with that and how if I had any engorgement or anything like that going on. Asking and then they always check into of course how much he's feeding and how often." Mothers described having nurses who were nice and approachable "The second child we had younger nurses, nicer nurses and they actually, they were very supportive." One mother said, "They were like, you know, you said you don't need help but I just wanted to check on you to make sure you're doing ok." Hospital staff helped mothers breastfeed, "The doctors and nurses were really knowledgeable and helpful." Having lactation consultants that were comfortable 
with their job was important "So I wanted to find people who were really outgoing and weren't shy about, about like getting in there and helping me like, 'Oh, that latch isn't right— - just re-do it,' you know," and "She was I felt very timid. She wasn't like in there like, 'You need to readjust the baby."”

Employer support. Some mothers described the ability to pump at work when they needed to, having a designated room to pump in, and being able to store their breast milk as supportive; working part-time is the only other employment factor that assisted with breastfeeding success. "I worked at Wal-Mart, and they were really supportive...they had a room set up for breastfeeding ...had an outlet, a private place to do it." Another mother shared "Um, that's kind of how this work environment is here though, I mean if you're pumping everybody is super supportive of it, so that's pretty awesome too cause a lot of workplaces aren't like it." Working part-time supported breastfeeding mothers "I only worked a day or two a week mostly, which helped because then I only had to struggle a couple of days." Another mother confirmed, "It's part-time through um, a family company, so I was able to take him with me." Some mothers were able to bring their babies to work and breastfeed. "Yea, yea I do parties and things, and I have people that are friends that I do parties with her... They are really supportive with me bringing her along; they usually have kids too." Working with family employers was also helpful with breastfeeding “I worked at my mom's resale shop. Um, well, I took them there with me."

\section{Steps Taken Toward Breastfeeding Success}

Rural resources. Rural geographic location was found to provide minimal resources for mothers wishing to breastfeed. Mothers who experienced breastfeeding success acknowledged this deficit and worked hard to find available resources: "I feel like there is not a lot of resources 
in the rural areas for it...I spent a lot of time researching and finding resources close or drivable to me." Another mother said, "I know so many of my mom friends and I, just quit breastfeeding really early, and I do feel like it's because we don't have many resources out here." One mother shared "I wish if women wanted to breastfeed that they would put the effort and resources in." Hospital selection was taken into consideration for breastfeeding success. One mother opted to deliver in an urban hospital: "Yea, so like St. Louis has some um, like international, boardcertified lactation consultants as opposed to our Health Department which does have some people who can help you, uh breastfeed and help you troubleshoot a little bit."

Intentional steps. Mothers described taking deliberate steps before delivery to assist with breastfeeding "So, while I was pregnant with my second I spent a lot of time researching, and I found a bunch of breastfeeding books." One mother confirmed, "I'm sure I googled a few things." Securing a doula to help with delivery was impactful with breastfeeding success. "I had a doula, and we talked about it almost every time I saw her, and the same with Robin that comes and sees me, and then with my OB." Taking prenatal classes through the hospital and Health Department was found to be supportive of breastfeeding "I took a class through here with my first. I come here to breastfeeding class here at the WIC, and I talked to her at the time. She actually came to the hospital with my first child, whenever the nurses wouldn't help me, and it's something that I really wanted to do.” Peer counselors from the Health Department supported breastfeeding mothers. "I talked to some of the peer counselors here. They've called and checked and see how everything was going and if I had any questions." Another mother confirmed, "I called her, and she come to my house." One mother described a book she found that was helpful with breastfeeding: "I don't even know if this book is going to be great, but it 
ended up being awesome- it was so such a good book! It basically takes you almost month by month through what you can expect when your breastfeeding."

Moreover, she shared "It was just a really great resource, and it was something I could, it's easy like the index and stuff are very clear." Simple suggestions such as "A nursing pillow is wonderful...way more comfortable," and being very proactive with travelling by carrying a cooler to store breast milk. "Yea, I take a little cooler...I just put the frozen bags, and I put in a cooler in the fridge, so then I can take it, get home, and freeze it." Finally, mothers were eager to take accountability for breastfeeding questions: "So, you know I still have googled different things and looked stuff on online."

Proper latch. Successful mothers learned how to help the baby latch correctly. "I had learned from the peer counselor how to latch on, how to hold the baby properly, that way it didn’t hurt me." Utilizing a routine for scheduling was also important: "Sticking with a routine of when we're going to feed and putting him on a schedule."

Proactive health. Mothers described proactive measures taken for personal health "I try to stay very hydrated, and I've spiked a fever with one, so I lost some of my supply um, but then again, we still had enough, so I think I just try to maintain a somewhat healthy diet." One mother shared, "He had a lot of allergies, so I had to change all of my eating habits and my whole diet to adjust to be able to stay nursing with him." Mothers were aware that their health was critical to breastfeeding success "You have to have...you have to know your diet and know your body. If you're low on calories one day, you need to try and make it up the following day." The consequence for mothers in this context of Breastfeeding Realized was that these mothers were able to breastfeed despite the oppositional barriers experienced. 


\section{Emerging Themes}

After gathering data from rural mothers, the single, core theory identified was Breastfeeding Success. Breastfeeding Success describes the ability of rural mothers to overcome many breastfeeding barriers in the rural environment. In the individual and social environment both psychological and physiological challenges confront rural mothers. The action-interaction data collected captured the successful breastfeeding mothers response to those challenges and were grouped into three main categories that helped to describe the single category of Breastfeeding Success: Matters of the Heart, Steps Taken Toward Breastfeeding Success, and Support to Succeed.

Mothers shared their excitement and determination to breastfeed. They describe breastfeeding rewards such as goal accomplishment, personal empowerment, joy, increased newborn health, and increased infant bonding. Mothers who experienced breastfeeding success took specific steps to ensure success: hospital selection, proactively identifying breastfeeding resources online and within driving distance, identifying breastfeeding support personnel (doula or peer support), and specific maternal nutritional steps. Mothers who were able to seek and receive breastfeeding support from family, hospital, and employer were able to breastfeed successfully. Family members who favored breastfeeding and supported the mother encouraged breastfeeding success. Hospital staff members, such as nurses and lactation consultants that were friendly, available, and knowledgeable about breastfeeding were able to encourage and support breastfeeding mothers. Some mothers described the need to select an urban hospital for delivery in order to encounter breastfeeding support.

Each mother interviewed had tried and failed to breastfeed with a previous infant.

Mothers who were successful with breastfeeding spoke to being determined to succeed, and one 
mother shared, "I was pretty determined I was going to breastfeed successfully this time!" Successful breastfeeding mothers acknowledged their rural barriers and found their breastfeeding facilitators - despite their rural location and lacking rural resources.

\section{Discussion}

The literature reviewed showed that most rural mothers are WIC participants, and return to work quickly. County statistics shared that $82 \%$ of residents are white, $41 \%$ work outside of the home, $9.5 \%$ have a college degree, average household members were two, and average household income for 2016 was $\$ 45,780$ (Vandalia Statistics). Mothers had a higher level of education with $80 \%$ having had some college. Mothers who worked outside the home was higher at 50\%; 50\% of mothers had four members living in their household, and all participants were white (see Table 2).

Eighty percent of rural mothers interviewed had some college education or a college degree. This finding was different from the education level depicted in the literature reviewed. Jacobson et al. (2015), Hohl et al. (2015), and Goodman et al. (2016) found that most rural mothers had less education. Hohl and colleagues (2016) found that the majority of rural mothers had some high school or had graduated from high school.

We found that most of our participants did work outside the home (50\%). This finding supports Flowers et al. (2008) who also found that many rural mothers receive WIC assistance and are employed at two months postpartum. Employers who were supportive of breastfeeding mothers were able to offer a private place for mothers to pump, storage for breast milk, and time for many breastfeeding breaks. Some mothers found working only part-time was best for breastfeeding, and some mothers were allowed to bring their babies with them to work to breastfeed. 
Hohl, Thompson, Escareno, and Duggan (2015) found that most participant mothers living in rural Washington State had an average income of $\$ 25,000$ to $\$ 35,000$. Our study participants had a smaller average household income than was described in the Hohl and colleagues (2015) study. Most of our participant families earned less than $\$ 20,000$ a year.

Fifty percent of mothers interviewed were married. This finding corroborates Flowers et al. (2008), who found the majority of rural mothers were married. While spousal support was appreciated and assisted in providing supportive encouragement for breastfeeding mothers, this researcher was surprised to find the spouse's opinion of breastfeeding did not impact the decision to breastfeed. The spouse had an insignificant role in breastfeeding decision-making. One mother shared 'I'm like, I'm going to do what I want to do. It's what's best for her."

The mothers' knowledge awareness of breastfeeding and the maternal and infant benefits of breastfeeding were surprising. This finding is confirmed by Murimi, Dodge, Pope, and Erickson (2010) who also found that the majority of their central Louisiana, rural WIC mothers were aware of the benefits of breastfeeding, but struggled with the lack of breastfeeding support. Rural mothers are entirely aware of why they should breastfeed; however, they continue to struggle with breastfeeding. All the mothers in this study, whether or not they breastfed successfully, understood the short and long-term benefits to both mother and infant from breastfeeding. Successful breastfeeding mothers acknowledged and anticipated breastfeeding barriers, and put specific steps in place to support their breastfeeding needs.

Goodman et al. (2016) found that rural hospitals and communities have gaps in breastfeeding support. Each participant interview reflects those gaps depicted in the literature. One hundred percent of our sampled mothers confirmed that there was very little breastfeeding knowledge with hospital nurses and lactation consultants. Hospital staff appeared uncomfortable 
with breastfeeding assistance and not friendly toward inquiring mothers. Some participants spoke of driving up to an hour away to find a breastfeeding-friendly hospital for delivery or breastfeeding support classes.

This study has demonstrated that rural mothers must be passionately motivated, positively supported by family and hospital staff, and receive employer support with breastfeeding. Due to the lack of rural breastfeeding resources, mothers who proactively identify drivable breastfeeding resources will be more likely to experience breastfeeding success.

\section{Limitations}

Because the sample of participants was recruited from a single health department in Midwestern, Illinois, these findings may not be generalizable to all rural locations. While the sample was representative of the Midwestern rural mother, all participants were receiving aid from WIC services and may not be representative of those rural mothers with a with a higher income or mothers with a more culturally diverse background.

\section{Implications}

While cultural attitudes of family support for breastfeeding rural mothers can sometimes be hard to encourage, the other factors involved with a rural mother's breastfeeding breakdown may be assessed and improved. Next steps entail ensuring that nurses and lactation consultants in rural areas are adequately trained on how to assist breastfeeding mothers immediately following infant delivery. In order to positively impact breastfeeding in rural mothers, postpartum care is a critical time to decrease breastfeeding anxiety and provide rural mothers with the knowledge and assistance required to combat the multiple breastfeeding challenges that rural mothers encounter. Encouraging mothers to inquire about employer breastfeeding support will help them to continue to breastfeed as they return to work quickly. Policy advocacy at the local 
and state level to increase funding for breastfeeding resources will help rural mothers breastfeed successfully. Sharing results of this study with rural hospitals will help hospitals identify supportive and detrimental breastfeeding support and care immediately following infant delivery.

\section{Conclusion}

Rural mothers should not receive disparate breastfeeding support, but rural hospitals have gaps in breastfeeding support. Ensuring that nurses and lactation consultants are trained and comfortable with breastfeeding is significant to breastfeeding success. Rural mothers and infants must be given equal access to breastfeeding support interventions so that they too may experience the maternal and infant health benefits that women living in urban environments receive. The rural mothers breastfeeding study results will help rural hospitals identify specific areas of need concerning mothers and breastfeeding support, and successful breastfeeding interventions could significantly impact rural public health outcomes. This study has identified a Breastfeeding Success theory that will help mothers overcome breastfeeding barriers and successfully breastfeed in the rural environment. The awareness of the rural mothers disparate breastfeeding support and the specific steps required to help rural mothers breastfeed will impact nursing education. 
CHAPTER III: LESSONS LEARNED FROM MANAGING RESEARCH WITH RURAL

\title{
MOTHERS
}

Chapter III describes unanticipated obstacles and lessons learned while conducting a study of rural mothers and their breastfeeding experience. This article is being prepared for publication in the Journal of Rural Health.

\begin{abstract}
Health care providers in rural areas face many challenges to providing breastfeeding support and services to mothers. Rural mothers struggle with both breastfeeding initiation and duration, while rural hospitals and communities have breastfeeding gaps. Both rural hospitals and rural communities have breastfeeding gaps. Some of the disparities identified include decreased breastfeeding support funding to rural hospitals and communities, limited patient breastfeeding education, and poor breastfeeding knowledge among nurses. Rural mothers were interviewed to share their experience with successful breastfeeding, and unexpected barriers and problems were experienced during data collection. The purpose of this article is to examine unanticipated obstacles to nursing research conducted during a study of rural mothers and their successful breastfeeding experience. Lessons learned from interacting with rural mothers are shared, and recommendations for improving nursing research are provided.
\end{abstract}

\section{Introduction}

Multiple research studies have shown that breastfeeding is the ideal source of nutrition for infants; however, many rural mothers do not breastfeed (McQueen, Dennis, Stremler, \& Norman, 2011; Wilhelm, Aguirre, Koehler, \& Rodehorst, 2015, Allen, Perrine, \& Scanlon, 2015). Duijts, Jaddoe, Hofman, and Moll (2010) found that breastfeeding provided health benefits to both infants and to breastfeeding mothers, including a decreased risk for chronic 
disease. Specifically, breastfeeding decreased maternal risk of breast and ovarian cancer and hypertension, and decreased incidence of type 2 diabetes mellitus (Duijts et al., 2010; McQueen et al., 2011, American Academy of Pediatrics, 2012). For infants, breastfeeding offers passive immunity from mothers whom breastfeed for three months (McQueen et al., 2011; Duijts et al., 2010). Further, McQueen and colleagues (2011) also found passive immunity provided infants protection against acute illness, such as ear and upper respiratory infections, as well as chronic diseases, such as obesity and diabetes. The purpose of this article is to examine unanticipated obstacles to nursing research conducted during a study of rural mothers and their breastfeeding experience.

\section{Background}

Rural hospitals have limited breastfeeding support practices when compared to urban hospitals (Allen, Perrine, \& Scanlon, 2015; Flower et al., 2008; Goodman, Majee, Olsberg, \& Jefferson, 2016). Rural mothers have poor breastfeeding initiation and duration rates and although many indicate a desire to breastfeed, the majority of mothers stop breastfeeding shortly after hospital discharge (Allen et al., 2015; Flower et al., 2008; Jacobson et al., 2015; Wilhelm, Aguirre, Koehler, \& Rodehorst, 2015). Specifically, Allen and colleagues (2015) found that $67 \%$ of mothers had stopped breastfeeding six weeks after infant delivery. Rural mothers find the lack of available breastfeeding support to be a challenge (Allen et al., 2015, Gazmararian et al., 2014; Goodman et al., 2016, Jacobson et al., 2015).

\section{Rural Breastfeeding Barriers}

Rural hospitals are less likely to receive funding when compared to urban hospitals (Allen et al., 2015; Goodman et al., 2016; Jacobson et al., 2015). Rural locations receive limited funding because most substantial funding is allocated to locations that provide services to the 
largest population, thus resulting in many barriers in providing breastfeeding support for rural mothers (Allen et al., 2015; Goodman et al., 2016; Jacobson et al., 2015). Maternity care practices that support breastfeeding differ in rural areas as compared urban practices (Allen et al., 2015; Flower et al., 2008; Goodman et al., 2016). Disparities in support include poor breastfeeding knowledge among hospital staff and decreased breastfeeding support from rural employers (Allen et al., 2015; Flower et al., 2008; Goodman et al., 2016). As a result, mothers living in rural locations have lower rates of breastfeeding initiation and decreased length of breastfeeding duration (Allen et al., 2015; Flower et al., 2008; Jacobson et al., 2015; Wilhelm et al., 2015). Researchers recommend that rural hospitals be targeted to promote interventions to improve breastfeeding practices, ultimately improving patient access to supportive services and resulting in better breastfeeding outcomes (Allen et al., 2015, Flower et al., 2008; Jacobson et al., 2015). Rural hospitals must collaborate with local health departments and other community agencies and combine resources to support mothers with a team approach (Flower et al., 2008; Hohl, Thompson, Escareno, \& Duggan, 2016; Goodman et al., 2016).

Researchers assert that continued breastfeeding support after hospital discharge is absent in rural communities (Flower et al., 2008; Goodman et al., 2016). In multiple studies, rural mothers have reported that hospital staff provided minimal information regarding community support for breastfeeding; researchers concluded that mothers should be given community breastfeeding support before and after infant delivery (Chen, Johnson, \& Rosenthal, 2012; Froehlich et al., 2015; Goodman et al., 2016; Jacobson et al., 2015). When studying breastfeeding behaviors, researchers found that fewer breastfeeding services are offered to rural mothers and rural mothers access prenatal care at lower rates than urban mothers (Allen et al., 2015; Flower et al., 2008; Gazmararian et al., 2014; Goodman et al., 2016; Jacobson et al., 
2015). Breastfeeding success in rural mothers is directly related to mothers receiving frequent, consistent support and reliable access to prenatal care (Flower et al., 2008; Jacobson et al., 2015; Gazmararian et al., 2014).

Written breastfeeding education and support materials may not be generalized to all mothers because health literacy varies (Chen, Johnson, \& Rosenthal, 2012; Froehlich et al., 2015; Gazmararian et al., 2014). Following delivery, postpartum mothers are physically exhausted, making retention of breastfeeding education difficult (Chen, et al., 2012; Froehlich et al., 2015; Gazmararian et al., 2014). Researchers have found that both rural providers and rural mothers believe new mothers are more likely to retain breastfeeding knowledge if it is provided immediately following hospital discharge, rather than just after delivery (Hohl et al., 2016; Flower et al., 2008; Gazmararian et al., 2014). Since learning styles vary, breastfeeding education should be offered in a variety of formats, including provision of written materials and visual aids (Froehlich et al., 2015; Gazmararian et al., 2014; Wilhelm et al., 2015).

Researchers have long debated whether the availability of supplemental infant formula inhibits breastfeeding success (Bolton et al., 2009; Dunn, Kalich, Henning, \& Fedrizzi, 2015; Murimi, Dodge, Pope, \& Erickson, 2010). Many hospitals have infant formula available upon request to both breastfeeding and non-breastfeeding mothers (Dunn et al., 2015). Murimi and colleagues (2010) investigated whether having formula available impacted duration of breastfeeding. They found that formula availability did not affect a mother's decision to breastfeed (Murimi et al., 2010). However, Bolton and colleagues (2009) and Dunn and colleagues (2015) found exposure to formula during hospital stay decreased breastfeeding initiation and duration significantly. Current researchers recommend that hospitals offer formula 
only as an exception, in order to improve breastfeeding rates (Bolton et al., 2009; Dunn et al., 2015).

Many rural mothers qualify for Women, Infant, and Children (WIC) services (Allen et al., 2015; Flower et al., 2008; Goodman et al., 2016; Jacobson et al., 2015). The purpose of WIC is to safeguard the health of low-income women, infants, and children who are at risk for experiencing nutritional deficits; low-income rural mothers experience poorer health outcomes than urban mothers (U.S. Department of Agriculture, Food and Nutrition Services, 2018). WIC participants in general, and specifically rural WIC participants, have an established nutritional risk and benefit from breastfeeding (Allen et al., 2015; Flower et al., 2008; Frick, Pugh, \& Milligan, 2012; Goodman et al., 2016; Olson et al., 2010). Improving breastfeeding support in rural areas could significantly affect health outcomes.

\section{Lessons Learned}

In a recent study by Borton, Pohl, Jenkins, Kerber, and Flannigan (2018), ten rural mothers were interviewed in an attempt to understand their breastfeeding experiences. This qualitative, grounded theory study investigated the experience of breastfeeding among rural mothers and this researcher developed a breastfeeding success theory. Those results are reported elsewhere (Borton et al., 2018). Throughout the study, this researcher found barriers to the conduct of research; these barriers involved both nurses and participants. This paper describes lessons we learned as researchers during the conduct of the study (see Figure 1).

\section{Stakeholder Buy-In}

The absence of stakeholder buy-in can be detrimental to research study implementation and completion. Early communications regarding study participation with the health department (HD) took place among the HD nursing director, the breastfeeding peer support specialist 
(BPSS), and myself as researcher. The two HD personnel were eager to support study participation and agreed to allow the researcher to attend clinic days to invite rural mothers to participate in the study. The BPSS suggested specific dates that I should attend clinic to recruit participants. No nurses were present in the HD on these days. When I tried to recruit participants on alternative days, I learned that the BPSS had been protecting me from the nursing staff. I was partway through an interview with a participant when a HD nurse interrupted me. She told the participant that she must complete her nurse visit prior to the interview. The HD nurse then informed me that I had disrupted her schedule. I apologized for the inconvenience, and explained that I would allow participants to have their nurse visit before their interview. However, in spite of my willingness to accommodate the nurses' schedule, no mothers were directed to me the remainder of the day. Subsequently, I conducted interviews only on the days that nurse visits were not scheduled.

Upon reflection, I realized that HD nurses had not been included in the planning of the interview process. I had not considered the potential inconvenience to nurses and they had not had the opportunity to provide feedback. The HD nurses have full schedules, with multiple mothers to see in a short period of time, and were noticeably frustrated by the deviation from their regular schedule. In retrospect, I should have taken time early in the process to solicit feedback from the HD nurses. Establishing relationships with stakeholders before study implementation can be critical to successful research completion (Wilhelm et al., 2015).

\section{Sample Characteristics}

Understanding the research population of interest is critical to successful data collection. In an effort to thank mothers for the time they invested in interviews, I offered them Wal-Mart gift cards. While many researchers use this technique, our participants did not appear to value 
gift cards or they may have felt uncomfortable sharing their home address with me. Given the participants' low-income status, I believed gift cards would be an appropriate incentive.

However, I had to ask repeatedly for mailing addresses in order to send them the cards. I

eventually realized they were not excited about receiving gift cards. I should have taken the time to interact with the sample population prior to implementation. I may have been able to find an incentive that was of value to them, or I may have realized that incentives were not important to this population.

\section{Identifying with Participants and Nurses}

Identifying shared interests between the researcher and participants can be helpful in establishing trusting relationships. My initial interactions with mothers and nurses were awkward and reserved. Mothers typically started the interview somewhat reluctantly and with very brief responses. When I shared with them that I had breastfed my four children, they became more eager to share their own breastfeeding experiences. Establishing common ground facilitated trust with more open interactions as a result.

Nurses were initially standoffish and reluctant to interact with me. Our relationship improved when I shared my own stories of working full time as a nurse while trying to care for my family. Surprisingly, the nurses seemed to be most impressed when they learned that I had driven 180 miles to interview their clients. I believe this demonstrated my dedication to and interest in rural, breastfeeding mothers.

\section{Recommendations for Action}

Nursing practice cannot improve without the successful conduct of nursing research. Nurse researchers face a variety of barriers. The barriers I encountered during the conduct of this study, and the lessons learned, could benefit other nurse researchers. 


\section{Lesson One: Stakeholder Buy-In}

Identifying key stakeholders and establishing stakeholder buy-in is critical for any research study. Stakeholders are more likely to be supportive when they understand the significance and vision of the research. I neglected to identify nurses as key stakeholders and subsequently did not get their buy-in. I recommend that researchers budget adequate time to visit the study site and meet face to face with stakeholders, explain the research, and solicit stakeholder feedback. Researchers may also wish to consider a pilot study. In addition to helping researchers gain a fuller understanding of participants and a clearer vision of potential barriers, pilot studies could also prevent researchers from overlooking important stakeholders.

\section{Lesson Two: Incentives}

Researchers commonly use incentives to encourage study participation (Groth, 2010); however, incentives are meaningless unless they are of value to participants.

Spending time with potential participants before study implementation may be helpful in assisting the researcher to encourage a trusting relationship and identify meaningful incentives. I assumed low-income mothers would appreciate Wal-Mart gift cards, but this was not the case. I recommend that researchers budget enough time in the research process to speak with potential participants about appropriate compensation.

\section{Lesson Three: Establishing Common Ground}

Qualitative researchers have found that establishing common ground with their participants enhances communication and builds trust (Jenkins, 2011). Researchers who are willing to share something of themselves with participants may find that establishing a trusting relationship is less challenging. Participants may feel more comfortable talking and sharing their own experiences when they think they have something in common with the researcher. 
Researchers should plan to spend additional time during interviews in order to identify shared interests and experiences and provide participants with a sense that the researcher understands them. When researchers understand participants' perspectives, they are more apt to represent their statements accurately.

\section{Conclusion}

A thorough exploration of rural mothers' breastfeeding experiences is underrepresented in the nursing literature. Investigating the breastfeeding experiences of rural mothers presented unanticipated obstacles. We have discussed three lessons learned in the conduct of breastfeeding research at a rural health department. Obtaining stakeholder buy-in, developing participant trust and identifying meaningful incentives, and using commonalities between participants and researcher can make the research process go more smoothly. 


\section{REFERENCES}

Abdulloeva, S., and Eyler, A. A. (2013). Policies on worksite lactation support within states and organizations. Journal of Women's Health, 22, 769-774.

Access. (n.d.) (2018). In Merriam-Webster's online dictionary (11th ed.). Retrieved from https://www.merriam-webster.com/dictionary/access

Allen, J. A., Perrine, C. G., \& Scanlon, K. S. (2015). Breastfeeding supportive hospital practices in the US differ by county urbanization level. Journal of Human Lactation, 31, 440-443.

American Academy of Pediatrics, Section on Breastfeeding, Breastfeeding and the use of human milk (2012). Pediatrics, 129: 827-41.

Blumer, H. (1969). Symbolic interactionism: Perspective and method. Englewood Cliffs, N.J: Prentice-Hall.

Bolton, T., Chow, T., Benton, P., \& Olson, B. (2009) Characteristics associated with longer breastfeeding duration: An analysis of a peer counseling support program, Journal of Human Lactation, 25(1), 18-27. DOI: 10.1177/0890334408325985.

Borton, R.E., Pohl, C., Jenkins, S., Kerber, C., \& Flannigan, P. (2018). The influence of social and economic factors on breastfeeding and among rural mothers. Manuscript in Preparation, Mennonite College of Nursing, Illinois State University, Normal, Illinois.

Breastfeeding and the Use of Human Milk, Section on Breastfeeding (2012) Pediatrics, 129 (3), 827-841. Doi: 10.1542/peds.2011-3552

Centers for Disease Control and Prevention. (2018). Breastfeeding report card-United States, 2018. Retrieved from https://www.cdc.gov/breastfeeding/pdf/2018breastfeedingreportcard.pdf 
Centers for Disease Control and Prevention. National Immunization Survey (NIS) website. Accessed August 1, 2018.

Chen, P., Johnson, L., \& Rosenthal, M. (2012) Sources of education about breastfeeding and breast pump use: What effect do they have on breastfeeding duration? An analysis of the infant feeding practices survey II. Maternal Child Health Journal, 16, 1421-1430. doi: 10.1007/s10995-011-0908-4.

City Data: Vandalia, Illinois (2018) Retrieved from http://www.city-data.com/city/VandaliaIllinois.html

Corbin, J., \& Strauss, A. (2015). Basics of qualitative research: Techniques and procedures for developing grounded theory (4th ed.). Thousand Oaks, CA: Sage Publishing.

Corless, L., Buckley, A., \& Mee, S. (2016) Power inequality between patients and nurses. Nursing Times; 112, (12-13) 20-21.

Cross-Barnet, C., Augustyn, M., Gross, S., Resnik, A., \& Paige, D. (2012). Long-term breastfeeding support: Failing mothers in need. Maternal and Child Health Journal, 16, 1926-1932. doi:10.1007/s10995-011-0939-x

Duijts, L., Jaddoe, V., Hofman, A., \& Moll, H. (2010). Prolonged and exclusive breastfeeding reduces the risk of infectious diseases in infancy. Pediatrics 18-25. doi:10.1542/peds.2008-3256

Dunn, R., Kalich, K., Henning, M., \& Fedrizzi, R. (2015) Engaging field-based professionals in a qualitative assessment of barriers and positive contributors to breastfeeding using the social ecological model, Maternal Child Health Journal, 19, 6-16. DOI 10.1007/s10995014-1488-X 
Dwyer, S.C., \& Buckle, J.L. (2009) The space between: On being an insider-outsider in qualitative research. International Journal of Qualitative Methods, 8(1), 54-63.

Flower, K. B., Willoughby, M., Cadigan, R. J., Perrin, E. M., \& Randolph, G. (2008). Understanding breastfeeding initiation and continuation in rural communities: A combined qualitative/quantitative approach. Maternal and Child Health Journal, 12, 402-414. doi:10.1007/s10995-007-0248-6

Frick, K.D., Pugh, L.C., \& Milligan, R.A. (2012) Costs related to promoting breastfeeding among urban low-income women. Journal of Obstetric Gynecological Neonatal Nursing, 41(1), 144-150. doi: 10.1111/j.1552-6909.2011.01316.x

Froehlich, J., Donovan, A., Ravlin, E., Fortier, A., North, J. \& Bloch, M. (2015) Daily routines of breastfeeding mothers, Work, 50, 433-442. DOI 10.3233/WOR-141954

Gamm, L. D., Hutchinson, L. L., Dabney, B. J., Dorsey, A. M. (2003). Rural healthy people 2010: A companion document to Healthy people 2010 (I). College Station, TX: The Texas A\&M University System Health Science Center, School of Rural Public Health, Southwest Rural Health Research Center.

Gazmararian, J., Dalmida, S., Merino, Y., Blake, S., Thompson, W., \& Gaydos, L. (2014). Maternal and Child Health Journal, 18, 839-851. doi: 10.1007/s10995-013-1308-8

Goodman, L. R., Majee, W., Olsberg, J. E., \& Jefferson, U. T. (2016). Breastfeeding barriers and support in a rural setting. MCN: The American Journal of Maternal Child Nursing, 41, 98103.

Groth, S. (2010). Honorarium or coercion: Use of incentives for participants in clinical research. The Journal of the New York State Nurses' Association, 41(1), 11-22. 
Hohl, S., Thompson, B., Escareno, M., \& Duggan, D. (2016). Cultural norms in conflict: Breastfeeding among hispanic immigrants in rural washington state. Maternal and Child Health Journal, 20, 1549-1557. doi:10.1007/s10995-016-1954-8

IBM Corp. Released 2013. IBM SPSS Statistics for Windows, Version 22.0 Armonk, NY: IBM Corp.

Jacobson, L. T., Twumasi-Ankrah, P., Redmond, M. L., Ablah, E., Hines, R. B., Johnston, J., \& Collins, T. C. (2015). Characteristics associated with breastfeeding behaviors among urban versus rural women enrolled in the Kansas WIC program. Maternal and Child Health Journal, 19, 828-839. doi:10.1007/s10995-014-1580-2

Jenkins, S. D. (2011). Conducting Transcultural Research: Critical Thinking in Thailand. Journal of Transcultural Nursing, 22 (1) 83-87.

Kramer, M. S., Aboud, F., Mironova, E., Vanilovich, I., Platt, R. W., Matush, L., . . Shapiro, S. (2008). Breastfeeding and child cognitive development: New evidence from a large randomized controlled trial. Archives of General Psychiatry, 65, 578-584.

Levesque, J., Harris, M., \& Russell, G. (2013). Patient-centered access to health care: conceptualizing access at the interface of health systems and populations. International Journal for Equity in Health, 12, 1-9.

McQueen, K. A., Dennis, C. L., Stremler, R., \& Normal, C. D. (2011). A pilot randomized controlled trial of a breastfeeding self-efficacy intervention with primiparous mothers. Journal of Obstetric, Gynecologic, and Neonatal Nursing: JOGNN, 40, 35-46. doi:10.1111/j.1552-6909.2010.01210.x 
Mickens, A. D., Modeste, N., Montgomery, S., \& Taylor, M. (2009). Peer support and breastfeeding intentions among black WIC participants. Journal of Human Lactation, 25, 157-162. doi:10.1177/0890334409332438

Murimi, M., Dodge, C., Pope, J., \& Erickson, D. (2010). Factors that influence breastfeeding decisions among special supplemental nutrition programs for women, infants, and children participants from central Louisiana. Journal of the American Dietetic Association, 110, 624-627. doi:10.1016/j.jada.2009.12.019

Olson, B. H., Haider, S. J., Vangjel, L., Bolton, T. A., \& Gold, J. G. (2010). A quasiexperimental evaluation of a breastfeeding support program for low income women in Michigan. Maternal and Child Health Journal, 14, 86-93. doi:10.1007/s10995-008-04305

Persad, M. D., \& Mensinger, J. L. (2008). Maternal breastfeeding attitudes: Association with breastfeeding intent and socio-demographics among urban primiparas. Journal of Community Health, 33, 53-60. doi:10.1007/s10900-007-9068-2

Pugh, L. C., Milligan, R. A., Frick, K. D., Spatz, D., \& Bronner, Y. (2002). Breastfeeding duration, costs, and benefits of a support program for low-income breastfeeding women. BIRTH, 29, 95-100.

Renfrew, M. J., McCormick, F. M., Wade, A., Quinn, B., \& Dowswell, T. (2012). Support for healthy breastfeeding mothers with healthy term babies. The Cochrane Database of Systematic Reviews, 16(5), CD001141. http://doi.org/10.1002/14651858.CD001141.pub4 Socioeconomic status. (2018). In the American Heritage New Dictionary of Cultural Literacy (3rd ed.). Retrieved from http://www.dictionary.com/browse/socioeconomic-status 
U.S. Census Bureau. (2016). Urban and rural definitions. Retrieved from https://www.census.gov/content/dam/Census/library/publications/2016/acs/acsgeo-1.pdf

U.S. Census Bureau. (2016). Urban and rural education levels. Retrieved from https://www.census.gov/newsroom/blogs/randomsamplings/2016/12/a_glance_at_the_age.html

U.S. Department of Agriculture, Food and Nutrition Service (2018). Women, infants, and children (WIC). Retrieved from https://www.fns.usda.gov/wic/about-wic-wics-mission

U.S. Labor Department. (2015). Data and statistics. Retrieved from https://www.dol.gov/wb/stats/stats_data.htm

U.S. Surgeon General (2010). The surgeon general's call to action to support breastfeeding. Retrieved from https://www.surgeongeneral.gov/library/calls/breastfeeding/factsheet.html

Wilhelm, S., Aguirre, T., Koehler, A., \& Rodehorst, T. (2015). Evaluating motivational interviewing to promote breastfeeding by rural Mexican-American mothers: The challenge of attrition. Issues in Comprehensive Pediatric Nursing, 38, 7-21. doi: $10.3109 / 01450862.2014 .971977$

Witters-Green, R. (2003). Increasing breastfeeding rates in working mothers. Families, Systems \& Health, 21, 415-434.

World Health Organization. (2016). Exclusive breastfeeding for six months best for babies everywhere. Retrieved from http://www.who.int/topics/breastfeeding/en/ 
BREASTFEEDING REVIEW OF LITERATURE

Figure A-1. PRISMA Flow Diagram/Search Strategy

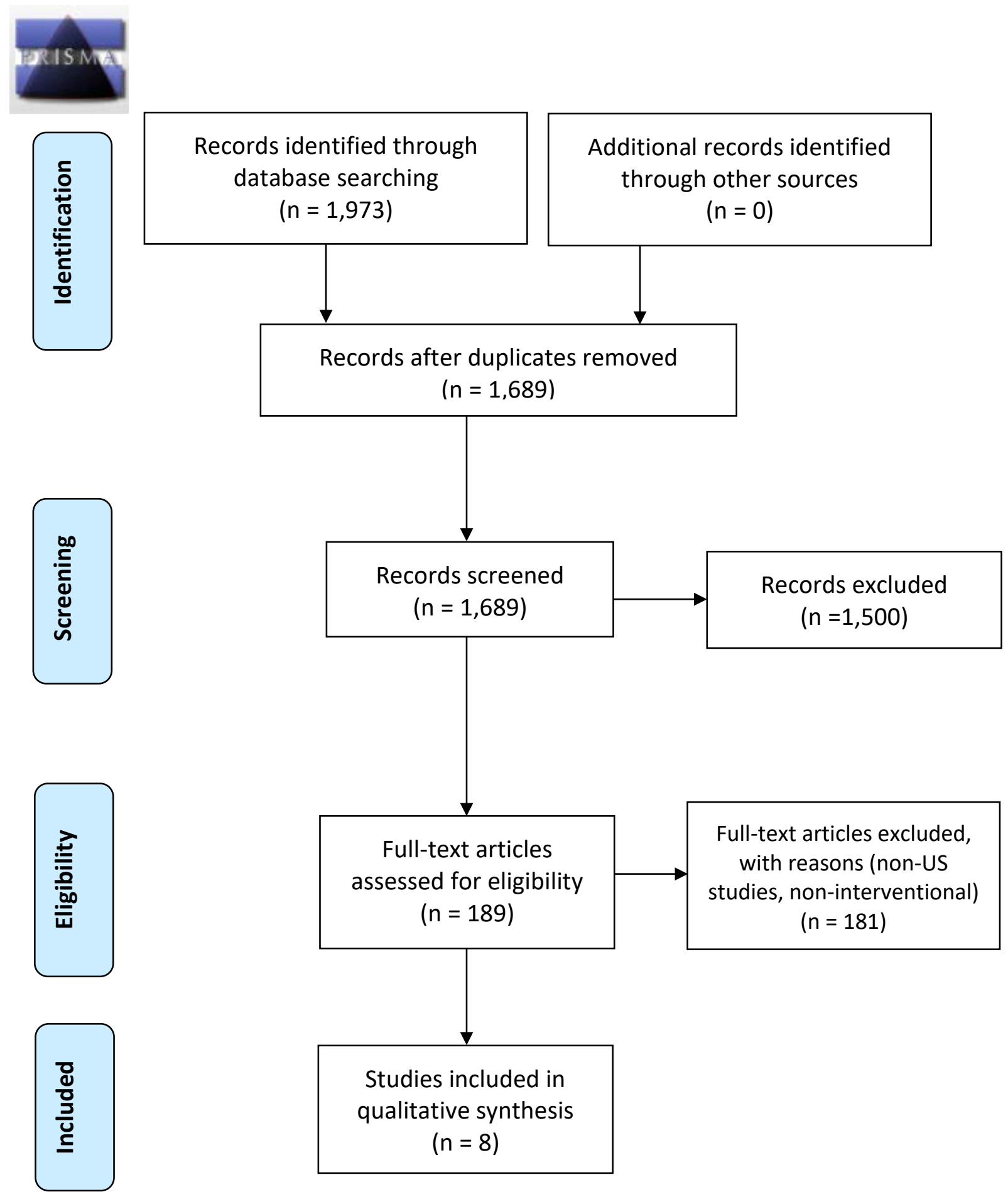


Table A-1

Evidence Table for Rural Breastfeeding Mothers and Breastfeeding Support Interventions

\begin{tabular}{|c|c|c|c|}
\hline $\begin{array}{l}\text { Title/Authors } \\
\text { Journal/Year }\end{array}$ & Purpose & Methods & Key Results \\
\hline $\begin{array}{l}\text { Breastfeeding supportive } \\
\text { hospital practices in the US } \\
\text { differ by county } \\
\text { urbanization level } \\
\text { Authors: } \\
\text { Allen, J. A. } \\
\text { Perrine, C. G. } \\
\text { Scanlon, K. S. } \\
\text { Journal: Journal of } \\
\text { Human Lactation } \\
\text { Year Published: } 2015\end{array}$ & $\begin{array}{l}\text { To describe whether } \\
\text { maternity care practices } \\
\text { supportive of breastfeeding } \\
\text { vary by county } \\
\text { urbanization level }\end{array}$ & $\begin{array}{l}\text { Sample: } \\
N=2666-2738 \\
\text { Study Design: } \\
\text { Retro case analysis }\end{array}$ & $\begin{array}{l}\text { Breastfeeding rates are } \\
\text { lower among infants living } \\
\text { in rural locations. } \\
\text { Interventions that } \\
\text { specifically target rural } \\
\text { hospitals may reduce the } \\
\text { gap in access to hospital } \\
\text { maternity care practices } \\
\text { supportive of } \\
\text { breastfeeding. }\end{array}$ \\
\hline $\begin{array}{l}\text { Title/Authors } \\
\text { Journal/Year }\end{array}$ & Purpose & Methods & Key Results \\
\hline $\begin{array}{l}\text { Understanding } \\
\text { breastfeeding initiation and } \\
\text { continuation in rural } \\
\text { communities: A combined } \\
\text { qualitative/quantitative } \\
\text { approach } \\
\text { Authors: } \\
\text { Flower, K. B. } \\
\text { Willoughby, M. } \\
\text { Cadigan, R. J. } \\
\text { Perrin, E. M. } \\
\text { Randolph, G. } \\
\text { Journal: Maternal and } \\
\text { Child Health Journal } \\
\text { Year Published: } 2008\end{array}$ & $\begin{array}{l}\text { To determine factors } \\
\text { associated with } \\
\text { breastfeeding in rural } \\
\text { communities }\end{array}$ & $\begin{array}{l}\text { Sample: } \\
N=1,292 \\
N=30 \\
\text { Study Design: } \\
\text { Longitudinal cohort study } \\
\text { Parallel ethnographic study }\end{array}$ & $\begin{array}{l}\text { Breastfeeding rates in rural } \\
\text { communities lag behind } \\
\text { national averages. } \\
\text { Opportunities for } \\
\text { increasing breastfeeding } \\
\text { rates in rural communities } \\
\text { include enhancing support, } \\
\text { maximizing role of WIC, } \\
\text { increasing hospital } \\
\text { breastfeeding assistance, } \\
\text { and creating approach } \\
\text { where the social } \\
\text { environment includes } \\
\text { breastfeeding as the norm. } \\
\text { Maternal employment \& } \\
\text { WIC }\end{array}$ \\
\hline $\begin{array}{l}\text { Title/Authors } \\
\text { Journal/Year }\end{array}$ & Purpose & Methods & Key Results \\
\hline $\begin{array}{l}\text { Breastfeeding barriers and } \\
\text { support in a rural setting } \\
\text { Authors: } \\
\text { Goodman, L. R. } \\
\text { Majee, W. } \\
\text { Olsberg, J. E. } \\
\text { Jefferson, U. T. } \\
\text { Journal: MCN: American } \\
\text { Journal of Maternal Child } \\
\text { Nursing } \\
\text { Year Published: } 2016\end{array}$ & $\begin{array}{l}\text { Describes breastfeeding } \\
\text { barriers and support in a } \\
\text { rural setting }\end{array}$ & $\begin{array}{l}\text { Sample: } \\
N=23 \\
\text { Study Design: } \\
\text { Community needs } \\
\text { assessment }\end{array}$ & $\begin{array}{l}\text { Gaps in hospital and } \\
\text { community breastfeeding } \\
\text { support were observed. } \\
\text { Need for stakeholders to } \\
\text { be involved with } \\
\text { breastfeeding } \\
\text { interventions. }\end{array}$ \\
\hline
\end{tabular}

(table continues) 


\begin{tabular}{|c|c|c|c|}
\hline $\begin{array}{l}\text { Title/Authors } \\
\text { Journal/Year }\end{array}$ & Purpose & Methods & Key Results \\
\hline $\begin{array}{l}\text { Characteristics associated } \\
\text { with breastfeeding } \\
\text { behaviors among urban } \\
\text { versus rural women } \\
\text { enrolled in the Kansas } \\
\text { WIC program } \\
\text { Authors: } \\
\text { Jacobson, L. T. } \\
\text { Twumasi-Ankrah, P. } \\
\text { Redmond, M. L. } \\
\text { Ablah, E. } \\
\text { Hines, R. B. } \\
\text { Johnston, J. } \\
\text { Collins, T. C. } \\
\text { Journal: Maternal and } \\
\text { Child Health Journal } \\
\text { Year Published: } 2015\end{array}$ & $\begin{array}{l}\text { To compare breastfeeding } \\
\text { behaviors in rural versus } \\
\text { urban locations and to } \\
\text { provide insight into } \\
\text { maternal demographics, } \\
\text { health, and lifestyle } \\
\text { behaviors among women } \\
\text { enrolled in the Kansas } \\
\text { WIC program }\end{array}$ & $\begin{array}{l}\text { Sample: } \\
N=17,067 \\
\text { Study Design: } \\
\text { Comparison analysis }\end{array}$ & $\begin{array}{l}\text { Urban and rural women } \\
\text { who were non-Hispanic } \\
\text { Black with some high } \\
\text { school education and } \\
\text { earned }<\$ 10 \mathrm{~K} \text { annually } \\
\text { were less likely to } \\
\text { breastfeed. } \\
\text { Availability of prenatal } \\
\text { services to rural women is } \\
\text { critical in breastfeeding } \\
\text { promotion success. }\end{array}$ \\
\hline $\begin{array}{l}\text { Title/Authors } \\
\text { Journal/Year }\end{array}$ & Purpose & Methods & Key Results \\
\hline $\begin{array}{l}\text { What new mothers need to } \\
\text { know: Perspectives from } \\
\text { women and providers in } \\
\text { Georgia } \\
\text { Authors: } \\
\text { Gazmararian, J. A. } \\
\text { Dalmida, S. G. } \\
\text { Merino, Y. } \\
\text { Blake, S. } \\
\text { Thompson, W. } \\
\text { Gaydos, L. } \\
\text { Journal: Maternal and } \\
\text { Child Health Journal } \\
\text { Year Published: } 2014\end{array}$ & $\begin{array}{l}\text { To explore the educational } \\
\text { needs of new mothers and } \\
\text { identify opportunities to } \\
\text { enhance healthcare } \\
\text { providers' current } \\
\text { educational efforts }\end{array}$ & $\begin{array}{l}\text { Sample: } \\
N=92 \\
\text { Study Design: } \\
\text { Two-part qualitative } \\
\text { methodology }\end{array}$ & $\begin{array}{l}\text { Mothers report difficulty } \\
\text { accessing and } \\
\text { understanding this } \\
\text { information. } \\
\text { Improved information will } \\
\text { improve maternal and } \\
\text { infant health. }\end{array}$ \\
\hline
\end{tabular}




\begin{tabular}{|c|c|c|c|}
\hline $\begin{array}{l}\text { Title/Authors } \\
\text { Journal/Year }\end{array}$ & Purpose & Methods & Key Results \\
\hline $\begin{array}{l}\text { Factors that influence } \\
\text { breastfeeding decisions } \\
\text { among Special } \\
\text { Supplemental Nutrition } \\
\text { Program for Women, } \\
\text { Infants, and Children } \\
\text { participants from Central } \\
\text { Louisiana } \\
\text { Authors: } \\
\text { Murimi, M. } \\
\text { Dodge, C. M. } \\
\text { Pope, J. } \\
\text { Erickson, D. } \\
\text { Journal: Journal of the } \\
\text { American Dietetic } \\
\text { Association } \\
\text { Year Published: } 2010 \\
\end{array}$ & $\begin{array}{l}\text { To determine the factors } \\
\text { that have the greatest } \\
\text { impact on the decision to } \\
\text { breastfeed, and to } \\
\text { determine the effect of } \\
\text { formula provided by WIC } \\
\text { on the initiation and } \\
\text { duration of breastfeeding } \\
\text { among WIC participants in } \\
\text { a rural parish in Central } \\
\text { Louisiana }\end{array}$ & $\begin{array}{l}\text { Sample: } \\
N=130 \\
\text { Study Design: } \\
\text { Cross-sectional study }\end{array}$ & $\begin{array}{l}\text { The results of this } \\
\text { breastfeeding study } \\
\text { suggest that the existing } \\
\text { WIC incentives do not } \\
\text { seem to be an important } \\
\text { factor in breastfeeding } \\
\text { decision making, which } \\
\text { may explain why the } \\
\text { majority of WIC } \\
\text { participants do not } \\
\text { breastfeed even though } \\
\text { they receive incentives. }\end{array}$ \\
\hline $\begin{array}{l}\text { Title/Authors } \\
\text { Journal/Year }\end{array}$ & Purpose & Methods & Key Results \\
\hline $\begin{array}{l}\text { Evaluating motivational } \\
\text { interviewing to promote } \\
\text { breastfeeding by rural } \\
\text { Mexican-American } \\
\text { mothers: The challenge of } \\
\text { attrition } \\
\text { Authors: } \\
\text { Wilhelm, S. L. } \\
\text { Aguirre, T. M. } \\
\text { Koehler, A. E. } \\
\text { Rodehorst, T. K. } \\
\text { Journal: Issues in } \\
\text { Comprehensive Pediatric } \\
\text { Nursing } \\
\text { Year Published: } 2015\end{array}$ & $\begin{array}{l}\text { To explore whether a } \\
\text { motivational interviewing } \\
\text { intervention could help } \\
\text { rural Mexican-American } \\
\text { mothers continue } \\
\text { breastfeeding. }\end{array}$ & $\begin{array}{l}\text { Sample: } \\
N=53 \\
\text { Study Design: } \\
\text { Two-group repeated } \\
\text { measures }\end{array}$ & $\begin{array}{l}\text { Although mothers in this } \\
\text { study intended to } \\
\text { breastfeed for } 6 \text { months, } \\
\text { most did not. Culturally } \\
\text { appropriate interventions } \\
\text { are needed to help rural } \\
\text { Mexican-American } \\
\text { mothers meet their } \\
\text { breastfeeding goals, } \\
\text { providing an opportunity } \\
\text { to reduce child risk of } \\
\text { multiple diseases and } \\
\text { obesity. }\end{array}$ \\
\hline $\begin{array}{l}\text { Title/Authors } \\
\text { Journal/Year }\end{array}$ & Purpose & Methods & Key Results \\
\hline $\begin{array}{l}\text { Cultural norms in conflict: } \\
\text { Breastfeeding among } \\
\text { Hispanic immigrants in } \\
\text { rural Washington State } \\
\text { Authors: } \\
\text { Hohl, S. } \\
\text { Thompson, B. } \\
\text { Escareño, M. } \\
\text { Duggan, C. } \\
\text { Journal: Maternal and } \\
\text { Child Health Journal } \\
\text { Year Published: } 2016\end{array}$ & $\begin{array}{l}\text { To examine perceptions, } \\
\text { experiences, and attitudes } \\
\text { toward breastfeeding } \\
\text { among Hispanic women } \\
\text { living in rural Washington } \\
\text { State. }\end{array}$ & $\begin{array}{l}\text { Sample: } \\
N=20 \\
\text { Study Design: } \\
\text { Qualitative } \\
\text { Exploratory }\end{array}$ & $\begin{array}{l}\text { Breastfeeding in mother } \\
\text { and child and cultural } \\
\text { practices are not enough to } \\
\text { encourage exclusive } \\
\text { breastfeeding to } 6 \text { months } \\
\text { in this Hispanic } \\
\text { population. } \\
\text { Continued support through } \\
\text { family-level interventions } \\
\text { and workplace policies } \\
\text { that encourage } \\
\text { breastfeeding is needed. }\end{array}$ \\
\hline
\end{tabular}

(end table) 
APPENDIX B: FIGURES, TABLES, AND SUPPLEMENTAL MATERIAL FROM CHAPTER

II: THE INFLUENCE OF SOCIAL AND ECONOMIC FACTORS ON BREASTFEEDING AND RURAL MOTHERS

Figure B-1. Breastfeeding Success Theory

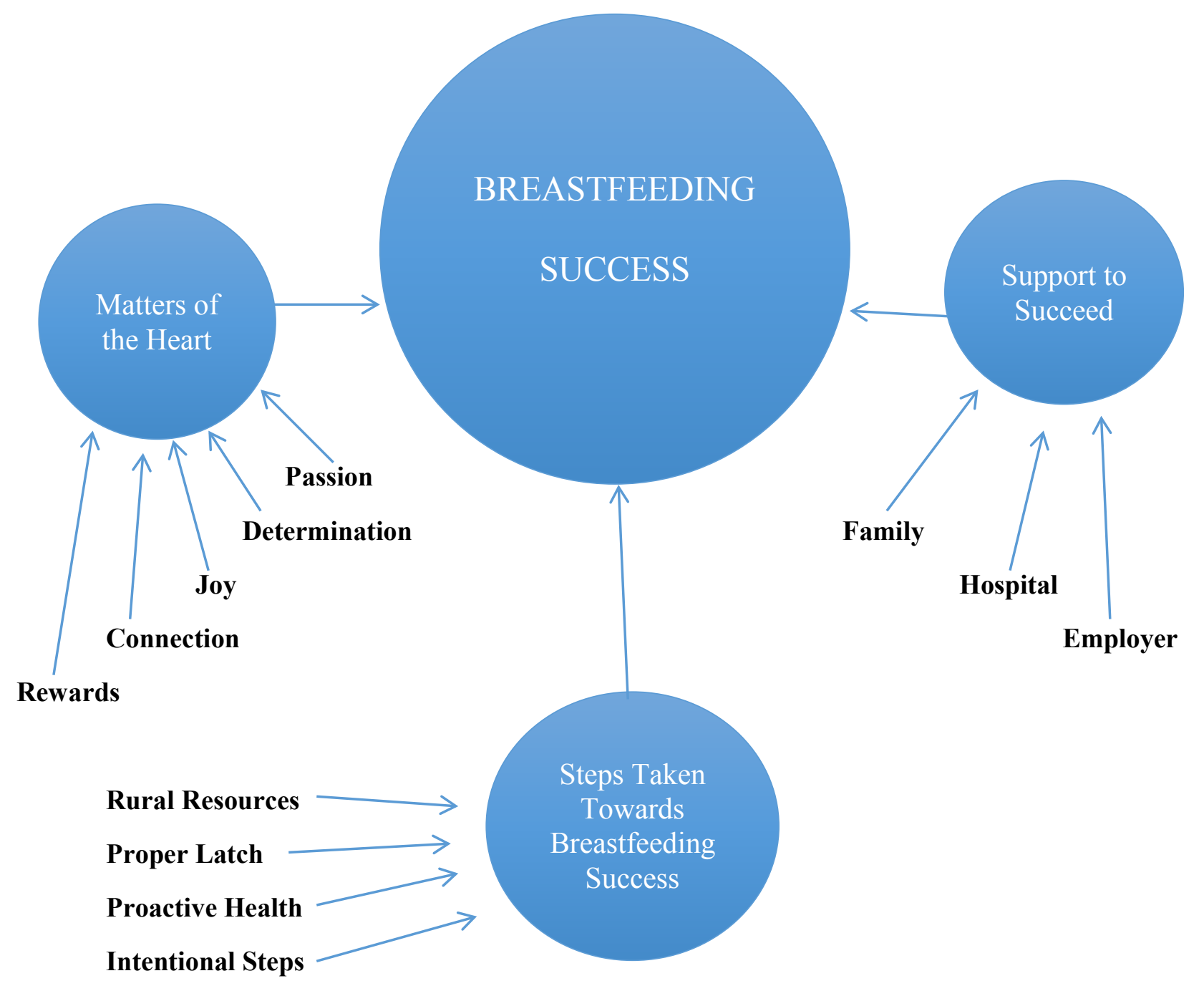


Table B-1

Average Rural Mother and Characteristics as a Percentage of the Sample

\begin{tabular}{lll}
\hline Characteristic & $\begin{array}{l}\text { Mother } \\
(n=10)\end{array}$ & Percentages \\
\hline
\end{tabular}

Age

29-30

5

50

Employment Status

Work outside the home

5

50

Annual Household Income

$<20,000$

4

40

Highest Level of Education

Some College

8

80

Number of Household Members

Four members

5

50

Marital Status

Married

5

50 


\section{Breastfeeding Experience Consent}

Dear Mother,

\section{Please read the following:}

I am Rachel Borton and am a graduate nursing student at Mennonite College of Nursing at Illinois State University. You are being invited to participate and share your experience, as a rural mother, with breastfeeding. Your participation is voluntary; there are no more risks involved than what you would encounter in daily life. Please read this form carefully. You will receive a copy of this paper to take with you. You will receive no compensation for participating in this study.

Purpose: To gain a better understanding of the rural mothers' breastfeeding experience.

Procedure: The Professional Investigator (PI) Dr. Carla Pohl and the Co-Professional Investigator (Co-PI) Rachel Borton will speak with you in person or on the phone and ask you about your breastfeeding experience. You will be able to ask questions about the breastfeeding study at any time during the interview. You may skip any questions that bother you, and you may stop the interview at any time. Your interview will be recorded using a voice recorder so that we can be sure we understand what you say. We will not record names; we will assign a pseudonym to your data and personal information. We do not want anyone to know who said what. The first interview will take about an hour of your time. Rachel will listen to the recording of the interview and take notes during the interview. A transcriptionist and Rachel Borton will type the interview. The notes will be shared with you during the second interview so that you can confirm or deny that our notes are correct. We want to make sure we have written and recorded precisely what you were trying to tell us. Your real name will not appear on the 
taped interview, any written notes taken during the interview, or the typed transcripts of the interview.

$\underline{\text { Risks and Benefits: }}$ The risks of this study are minimal, no more than what you would encounter in a normal life. You may choose to not participate at any time. The risks can be emotional discomfort because you may feel emotionally distressed by recounting your breastfeeding or birth experience. The other risk could be an unintentional breach of confidentiality. Rachel and Carla are experienced nurse practitioners, with extensive experience dealing with clients in physical and emotional distress and will be happy to talk to you about any distress or refer you to support services if needed. Your name will be kept confidential throughout the entire process, to help protect against a breach of confidentiality. There may be no personal benefit from answering these questions. What we learn from you may help in understanding the rural mother's breastfeeding experience. It may help us provide breastfeeding support to rural mothers.

Privacy and Confidentiality: The interview is entirely confidential, and your name will not be used for any purpose whatsoever. Once the study is completed, the results will be analyzed without any personal identifiers and may be presented at a professional conference and published in a professional journal.

All study data will be stored at the primary investigator's office in a locked cabinet stored in a locked room. Electronic data will be stored on a password-protected computer.

You do not have to participate in the interview, and you may leave anytime that you want to without punishment. If you don't come to the interview or speak on the phone no one will know; your WIC or any other services will not be affected. If you have any questions about this 
breastfeeding experience study, please call Rachel Borton and/or email. If you have questions about your rights as a research participant, or if you feel you have been placed at risk, please call the Research Ethics \& Compliance Office and/or email.

\section{Mennonite College of Nursing, Illinois State University}

Please place an $\mathrm{X}$ in front of yes or no.

Yes I want to come to the interview or speak on the phone. I know that it will be recorded. I have read this consent form and have had the opportunity to have my questions answered to my satisfaction. I voluntarily agree to participate in this breastfeeding experience study. I understand that a copy of this consent will be provided to me for future reference.

No I do not wish to participate.

Participant Signature Date

Thank you for your participation!

Rachel Borton, PhDC , MSN, FNP-BC

Graduate Student, Ph.D. program

Mennonite College of Nursing

Illinois State University 


\section{Mental Health Resources}

1. Community Resource Center

Mental Health Service

421 W Main St · (618) 283-4229

2. T.E.C.S. Counseling

Counselor

1121 N 6th St · (618) 283-2222

Open until 7:00 PM 


\section{Rural Breastfeeding Participant Flyer:}

Hi! My name is Rachel; I am a Family Nurse Practitioner working on my Ph.D. in Nursing. I am interested in hearing about your breastfeeding experience. I would like to meet with you in person or speak with you on the phone about your experiences with breastfeeding. Please contact me at XXX-XXX-XXXX and email at $\operatorname{xxxxxxxxxxxxxx.~}$

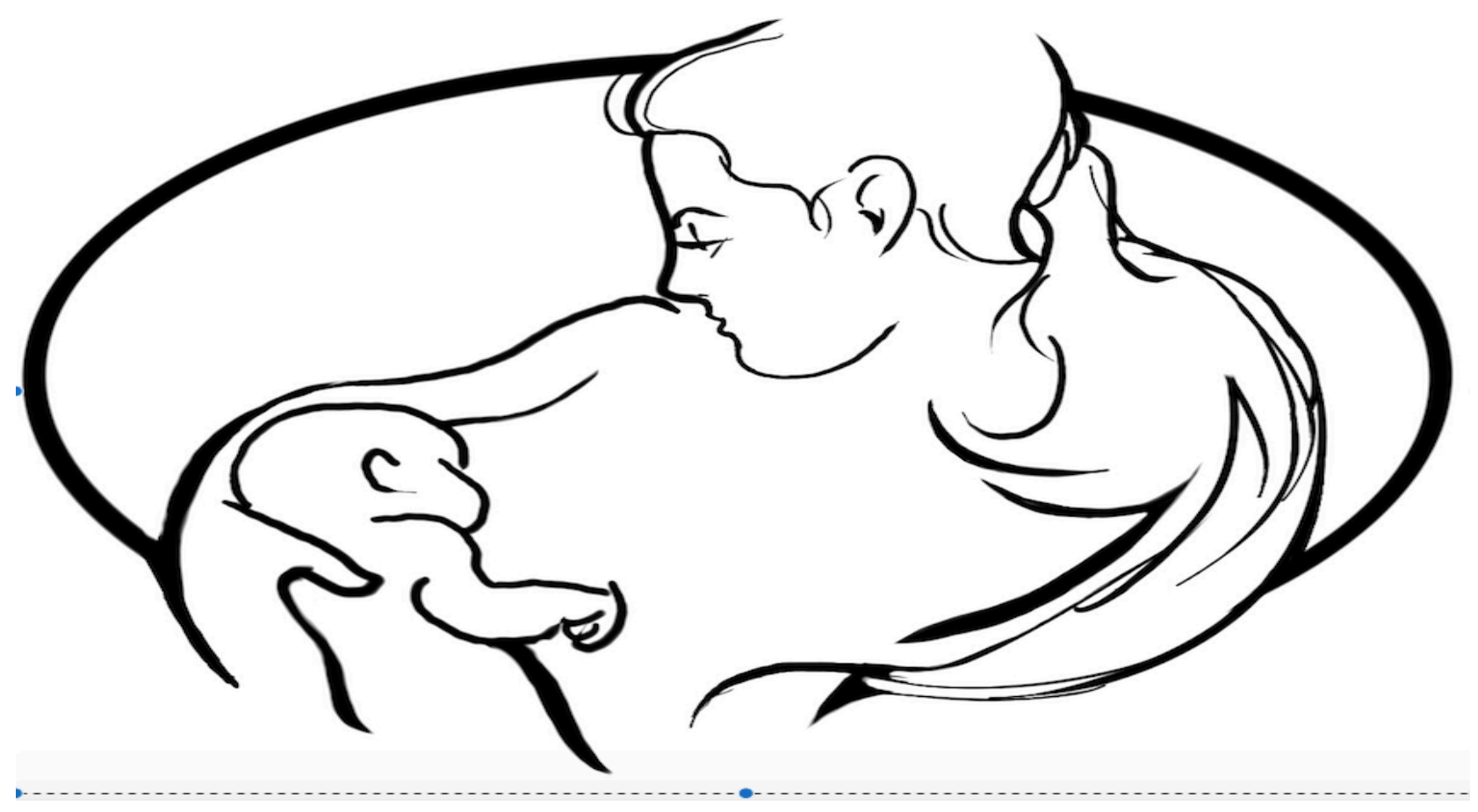


Interview Protocol: Interactions of Social and Economic Factors for Breastfeeding Mothers

\section{in a Rural Setting}

Time of Interview:

Date:

Place:

Interviewer:

Interviewee:

Study Purpose:

The purpose of this study is to understand your experiences with breastfeeding.

Question Examples:

Think back to when you were pregnant and thought about how to feed your baby. Tell me about that time.

Prompts: What about your family?

Follow-up: Can you tell me about any other information you looked at or people you talked to? What has helped you breastfeed over the past six months?

Would you tell me about breastfeeding your baby?

Think back to when you were breastfeeding. Do you remember if anything has helped support your breastfeeding?

Tell me about returning to work? Would you talk to me about breastfeeding at work? 
Do you know anyone else who I could talk to about her breastfeeding experience?

Is there anything else you would like to tell me?

Interview Conclusion:

Thank you for sharing your experience with me. Everything you have said will be kept confidential. I will mail you a written copy of the interview to be sure I heard you correctly.

Observed nonverbal behaviors: 


\section{Breastfeeding Success Memo}

\section{Memo 1}

June $25^{\text {th }}, 2018$

Concept: Hospital Support

Field Note Exert: It was such a life or death thing, very traumatic. The same nurse kept coming in, and they would supplement with formula, and every time I tried, I would get really anxious that it wasn't happening and then I just switched to formula. (Quote from the interview with subject \#3)

This woman is describing her "hospital support" provided by the nurses immediately following her delivery. She described being fearful that her baby was not getting enough milk and she was told the baby's blood sugar was low, and she was so anxious that her baby was not getting enough milk and that her baby would die.

Mothers who did not breastfeed successfully described being anxious and worried about breastfeeding their infant and not receiving appropriate support from hospital nurses.

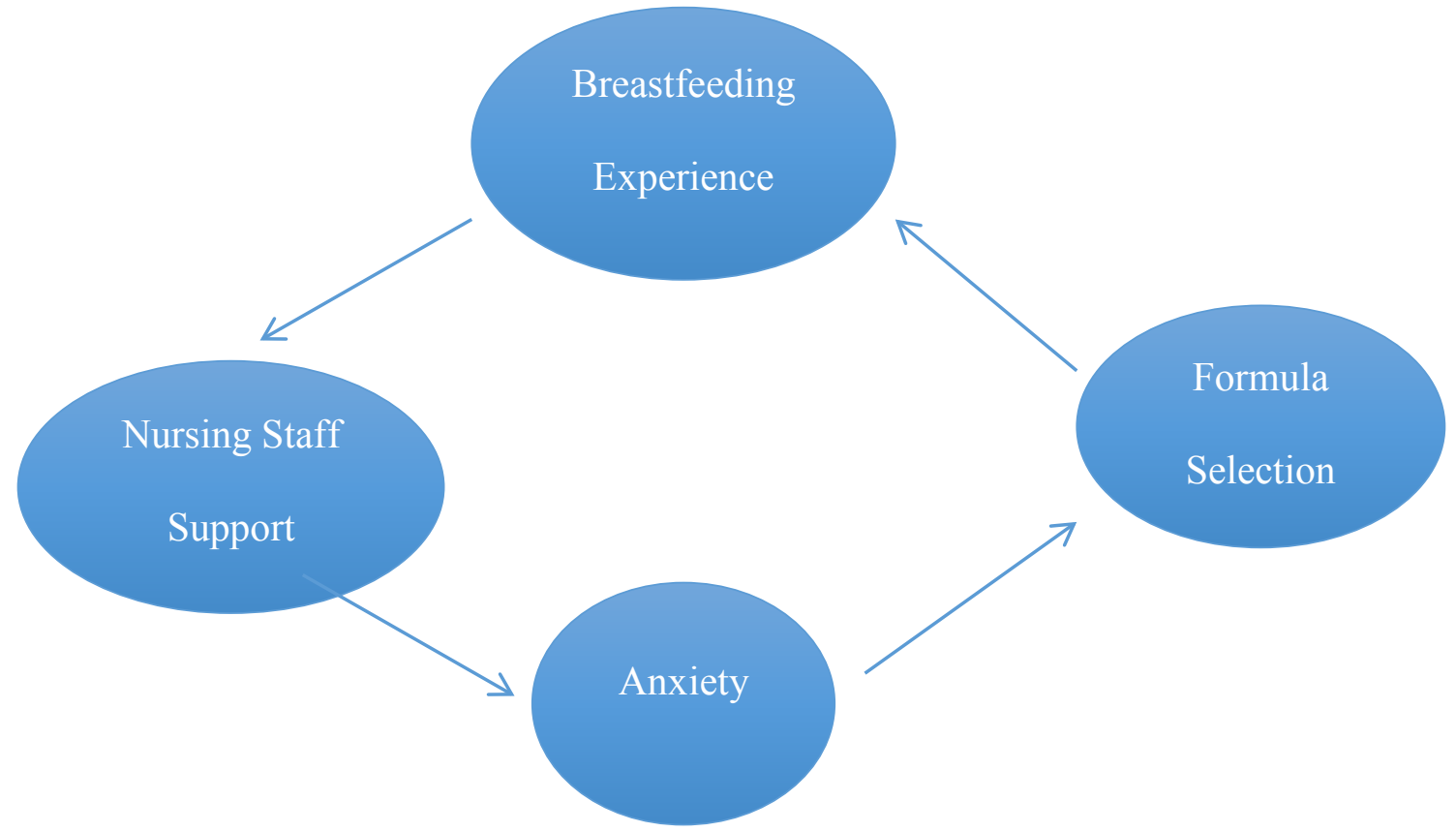

Figure B-2. Early Diagram on the Concept of Hospital Support 


\section{Observation and Field Notes}

\section{Field Notes 1}

\section{Descriptive Information:}

Friday, April $6^{\text {th }}$, the local diner in rural town, the temperature is cold outside, windy and 48 degrees. The diner has eight tables in total. Three tables occupied, one waitress who is also the cashier and host. One table occupied by two older men in bib overalls, eating a large meal and speaking and laughing frequently. Two older women, wearing nice-to- casual clothing, eating, and talking, occupy the other table. One younger man is seated, waiting for takeout. The single waitress is excited to learn that I am visiting from another town and that I am inquiring about their special pasta of the day. The waitress is happy to answer my questions.

\section{Reflective Information:}

The diner is small, very plain, but demonstrated a very warm, and welcoming atmosphere. Either the diner does not get too many visitors, or there is a great sense of pride in the community as the waitress was eager to answer my questions-probably a combination of both! The diner appears to be an excellent place for social interaction during colder weather. The men in the diner looked like farmers, and the women looked to be about retirement age. No young people present, other than the man waiting for takeout and the waitress. 


\section{APPENDIX C: FIGURE FROM CHAPTER III: LESSONS LEARNED FROM MANAGING RESEARCH WITH RURAL MOTHERS}

Figure C-1. Lessons Learned

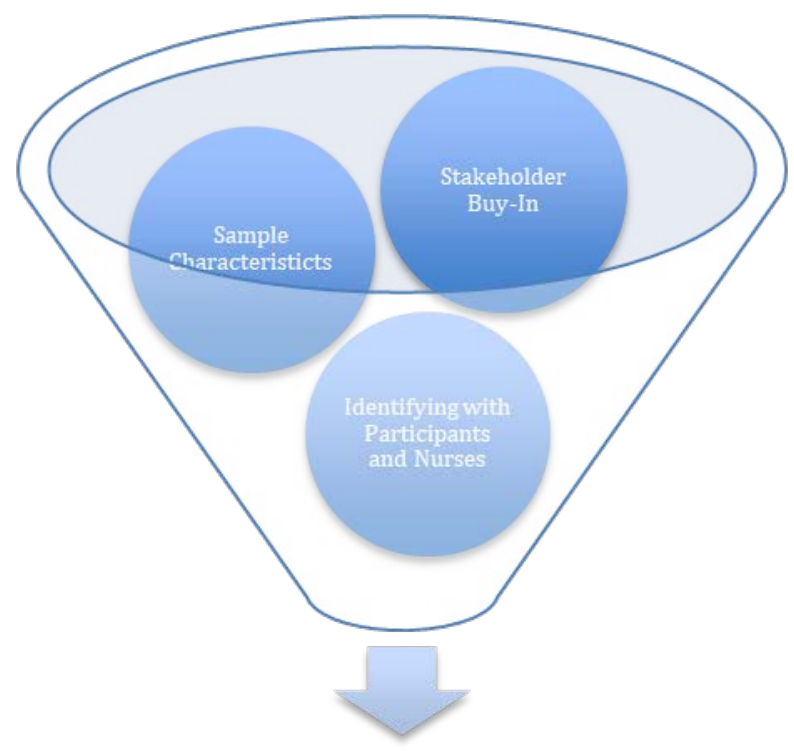

Nursing Research Success 